\title{
Lithological Classification Using Sentinel-2A Data in the Shibanjing Ophiolite Complex in Inner Mongolia, China
}

\author{
Wenyan Ge ${ }^{1}\left(\mathbb{D}\right.$, Qiuming Cheng ${ }^{2}$, Yunwei Tang ${ }^{3}$, Linhai Jing ${ }^{3, *}$ and Chunsheng Gao ${ }^{1}$ \\ 1 School of Earth Sciences and Resources, China University of Geosciences (Beijing), Beijing 100083, China; \\ 3001150120@cugb.edu.cn (W.G.); 2101170018@cugb.edu.cn (C.G.) \\ 2 State Key Lab of Geological Processes and Mineral Resources, China University of Geosciences (Beijing), \\ Beijing 100083, China; qiuming.cheng@iugs.org \\ 3 Institute of Remote Sensing and Digital Earth, Chinese Academy of Sciences, Beijing 100094, China; \\ tangyw@radi.ac.cn \\ * Correspondence: jinglh@radi.ac.cn; Tel.: +86-108-217-8106
}

Received: 4 April 2018; Accepted: 18 April 2018; Published: 20 April 2018

\begin{abstract}
As a source of data continuity between Landsat and SPOT, Sentinel-2 is an Earth observation mission developed by the European Space Agency (ESA), which acquires 13 bands in the visible and near-infrared (VNIR) to shortwave infrared (SWIR) range. In this study, a Sentinel-2A imager was utilized to assess its ability to perform lithological classification in the Shibanjing ophiolite complex in Inner Mongolia, China. Five conventional machine learning methods, including artificial neural network (ANN), $k$-nearest neighbor ( $k$-NN), maximum likelihood classification (MLC), random forest classifier (RFC), and support vector machine (SVM), were compared in order to find an optimal classifier for lithological mapping. The experiment revealed that the MLC method offered the highest overall accuracy. After that, Sentinel-2A image was compared with common multispectral data ASTER and Landsat-8 OLI (operational land imager) for lithological mapping using the MLC method. The comparison results showed that the Sentinel-2A imagery yielded a classification accuracy of $74.5 \%$, which was $2.5 \%$ and $5.08 \%$ higher than those of the ASTER and OLI imagery, respectively, indicating that Sentinel-2A imagery is adequate for lithological discrimination, due to its high spectral resolution in the VNIR to SWIR range. Moreover, different data combinations of Sentinel-2A + ASTER + DEM (digital elevation model) and OLI + ASTER + DEM data were tested on lithological mapping using the MLC method. The best mapping result was obtained from Sentinel-2A + ASTER + DEM dataset, demonstrating that OLI can be replaced by Sentinel-2A, which, when combined with ASTER, can achieve sufficient bandpasses for lithological classification.
\end{abstract}

Keywords: Sentinel-2A; machine learning methods; maximum likelihood classification; lithological map

\section{Introduction}

There are about $5 \%$ of territories in China that belong to Gobi Desert, mainly distributed in the Northwest China. Due to vastness, poor accessibility, and atrocious weather conditions in these areas, regional lithological mapping in the field is costly and challenging. As an economical and efficient technique, remote sensing has become a popular method for regional lithological mapping, especially in arid and semi-arid regions [1-4]. Optical imagery acquired by spaceborne and airborne sensors has been widely applied to mineral and lithological exploration for decades. For instance, the United States Geological Survey (USGS) used ASTER (Advanced Spaceborne Thermal Emission and Reflection Radiometer) data to map the hydrothermally altered rocks in the central and southern parts of the Basin and Range province of the United States [5]. 
Due to its lower cost and higher accessibility than hyperspectral data, multispectral imagery, such as Landsat-5 TM, Landsat-7 ETM+ (enhanced thematic mapper plus), Landsat-8 OLI (operational land imager), and ASTER, is broadly utilized to extract lithologic, mineral, and structural information in metallogenic provinces [6-8]. As one of the world's earliest and longest continuously acquired collection of spaceborne moderate-resolution land remote sensing data, the Landsat series has been applied in geology for decades [6,9-11], for applications such as hydrothermal alteration (ferric iron and hydroxides) extraction, lithological discrimination, and geotectonic interpretation. With a higher spectral resolution in the shortwave infrared (SWIR) and thermal infrared (TIR) range than other multispectral data, ASTER provides a higher potential to undertake semi-quantitative mineral mapping. It has become the most popular imagery in geological exploration, especially in hydrothermal alteration and lithological unit discrimination, since the Terra satellite was launched in 1999 [7,12-14]. For example, Son et al. [15] utilized ASTER data to map distribution patterns of hydrothermal alteration and igneous rocks in the southwestern Gobi in Mongolia. Yoshiki et al. [16] applied ASTER TIR (thermal infrared) images to map regional lithological rocks in the Tibetan Plateau. However, with Landsat 7 being damaged in 2003 and Landsat 5 retiring in 2013, only Landsat 8, launched in 2013, remains within the Landsat mission for routine operation. Moreover, due to an anomalously high SWIR detector temperature, ASTER SWIR data have been unavailable since April 2008.

Thereafter, the Sentinel-2 mission, launched by the European Space Agency (ESA), acts as important data continuity and enhancement for the Earth observation. The Sentinel-2 Multi-Spectral Imager (MSI) consists of identical Senitnel-2A and Sentinel-2B, which were launched on 23 June 2015 and 7 March 2017, respectively. With a short revisit time (every 5 days with two satellites), the Sentinel-2 missions aimed at global monitoring for environment and security, such as forest monitoring, land cover change detection, and natural disaster management $[17,18]$. In addition, the high-resolution Sentinel-2 multispectral data were confirmed to have potential for mineral mapping in geological investigations in the last several years, especially for the iron absorption feature, due to the similar or even higher spectral setting than Landsat series and SPOT in the VNIR region [19-21]. However, there is rare research exploring the capability of Sentinel-2 data for complex lithological classification.

Although it is not new to use remote sensing technique for lithological classification in geological investigation $[2,22,23]$, many studies are limited, due to the coarse spatial/spectral resolutions of multispectral data, causing difficulties in accurately classifying rock units [22]. As a solution, multiple ancillary data with texture information, such as airborne geophysical data [24], DEM [25], and geomorphic feature [2], can be integrated with multispectral imagery for improved lithological classifications [22]. However, the integration of multispectral data with different bandpasses for lithological classification is of little concern in previous literature.

In this study, lithological classification was performed in the Shibanjing ophiolite complex in the Beishan orogenic belt in Inner Mongolia, China. The present research aims at investigating the potential of the Sentinel-2A and the integrations of multispectral imagery for lithological classification in the Shibanjing ophiolite complex. Specifically, (i) five typical machine learning methods, including artificial neural network (ANN), $k$-nearest neighbor ( $k$-NN), maximum likelihood classification (MLC), random forest classifier (RFC), and support vector machine (SVM), were compared to select the optimal classifier for lithological classification using the data combination of Sentinel-2A and DEM (Sentinel-2A + DEM); (ii) three data combinations, OLI + DEM, ASTER + DEM, and Sentinel-2A + DEM, were employed to classify lithological units, which aimed to evaluate the capability of Sentinel-2A for lithological mapping; and (iii) two data combinations, OLI + ASTER + DEM and Sentinel-2A + ASTER + DEM, were utilized to compare the capability of different combinations of multispectral bands for lithological classification. 


\section{Materials and Methods}

\subsection{Study Area Description}

The study area is located at $41^{\circ} 31^{\prime} 24^{\prime \prime}-41^{\circ} 36^{\prime} 26^{\prime \prime} \mathrm{N}$ and $98^{\circ} 19^{\prime} 15^{\prime \prime}-98^{\circ} 29^{\prime} 53^{\prime \prime} \mathrm{E}$. It consists of the Shibanjing ophiolite in Beishan orogenic belt in Inner Mongolia, China (Figure 1a). The Beishan orogenic belt, located in the southern part of the Central Asian Orogenic Belt (CAOB), is composed of ophiolites, arcs, and blocks formed by subduction-accretion between the Tarim craton and the Kazakhstan plate [26] (Figure 1b). The Beishan orogenic belt represents a major part of the southern $\mathrm{CAOB}$, which makes it a critical area for unraveling the evolution and accretionary orogenic history of the CAOB [27]. There are several complete ophiolites in the Beishan orogenic collage, which possibly formed in the early Paleozoic era in the southern CAOB. From north to south, three main ophiolitic belts are distributed along the Beishan orogenic belt: the Hongshishan ophiolitic belt, the Mingshui-Shibanjing-Xiaohuangshan ophiolitic belt, and the Hongliuhe-Niujuanzi-Xichangjing ophiolitic belt, as shown in Figure 1b [28].

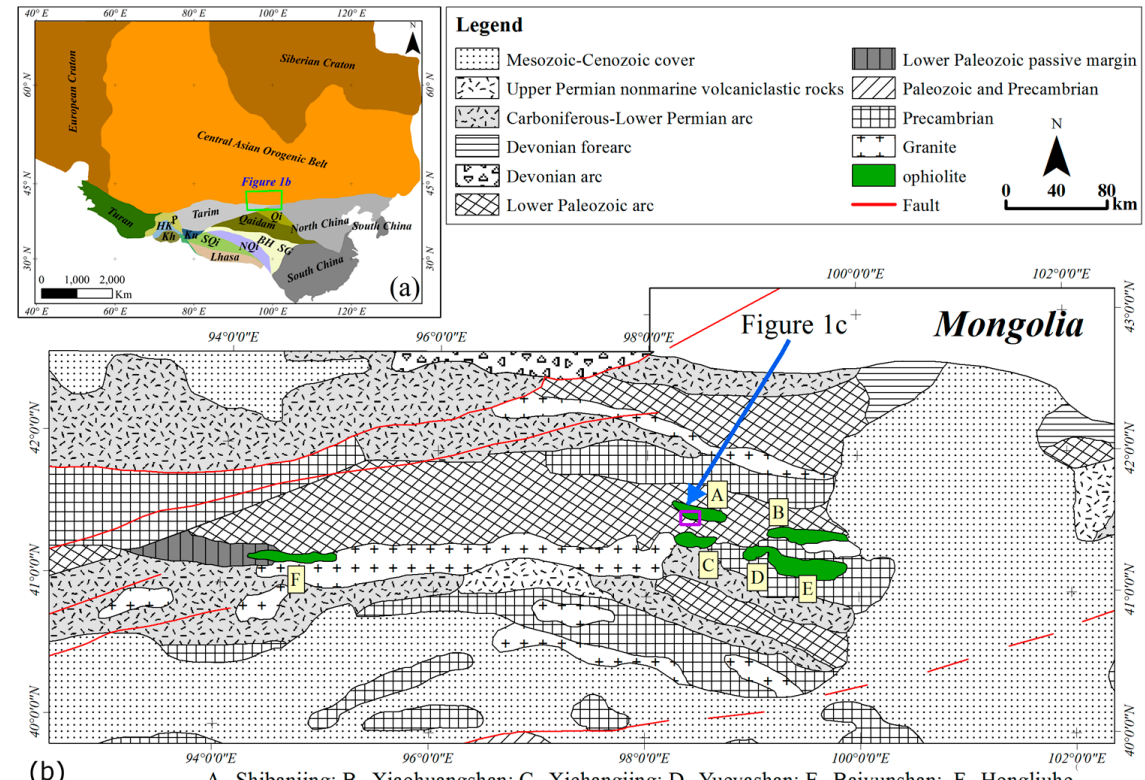

(b)

A--Shibanjing; B--Xiaohuangshan; C--Xichangjing; D--Yueyashan; E--Baiyunshan; F--Hongliuhe

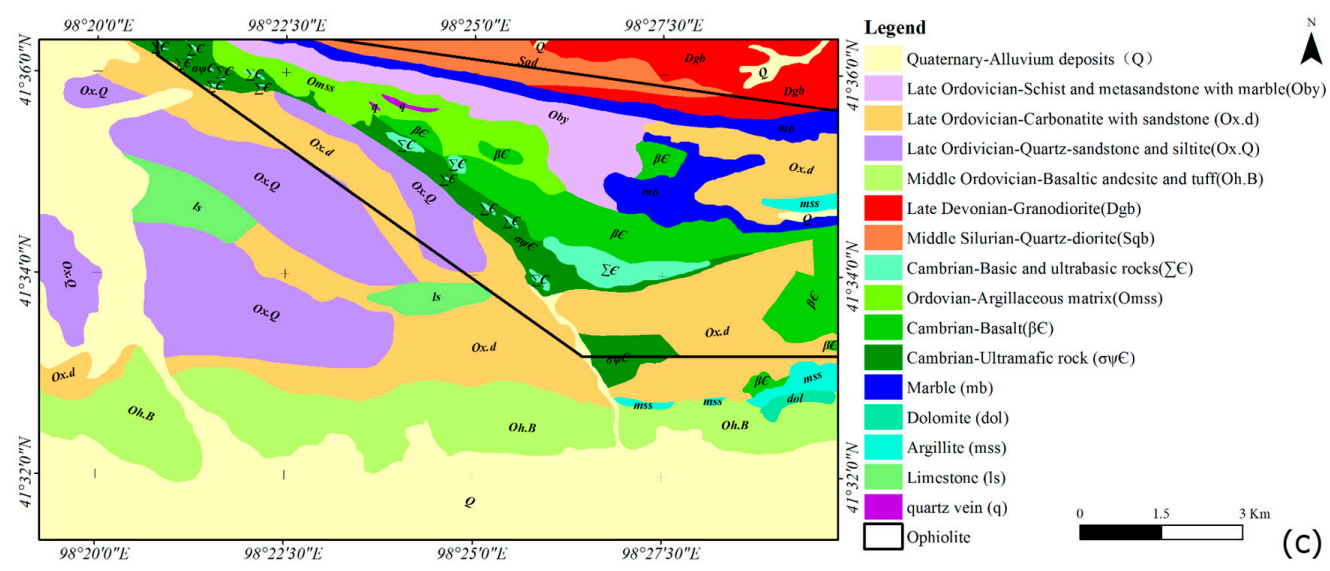

Figure 1. (a) Simplified tectonic index map showing the position of Beishan orogenic belt, modified after Jolivet [29]. BH, Bayan Har; HK, Hindu Kush; Kh, Kohistan; Ku, Kudi; NQi, North Qiangtang; P, Pamir; Qi, Qilian Shan; SG, Songpan-Garze; SQi, South Qiangtang. (b) simplified geological map of the western Beishan orogenic belt, modified after Davis et al. [30]; and (c) geological map of the Shibanjing ophiolite. 
The Shibanjing ophiolite complex is in the Mingshui-Shibanjing-Xiaohuangshan ophiolite belt, which is approximately $80 \mathrm{~km}$ away from the Xiaohuangshan ophiolite (Figure 1b). Structure activities in the complex area are intense and characterized by NW strike-slip faults, which are the main faults controlling the distribution of formation and magmatic rocks. The ophiolite complex is characterized by tectonic slices of ophiolitic rocks, including meta-ultramafic rocks, mylonitic gabbros, metabasalts, and clastic rocks in a matrix of turbidites, and the mélange contains blocks of argillaceous matrix and marble, where many ophiolitic rocks in the complex experienced amphibolite facies metamorphism [31-33], as shown in Figure 1c. The emergent strata are Cambrian, Ordovician, Silurian, Devonian, and Quaternary. The magmatic rocks are dominated by the felsic intrusion, and the mafic and ultrabasic rock unit is one of the important rock units that make up the ophiolitic complex. The basic and ultrabasic rocks mainly consist of pyroxenite, olivinite, and augite peridotite (Figure 1c). The geological map of the Shibanjing ophiolite complex displayed in Figure 1c was generated via visual interpretation of remote sensing data, and then verified and modified in the field in June 2016. The arid study area with sparse vegetation cover and well-exposed rocks is an ideal region to test lithological mapping by remote sensing data.

\subsection{Datasets and Data-Preprocessing}

\subsubsection{Data-Preprocessing}

Three types of multispectral imagery, Sentinel-2A, ASTER and OLI, were downloaded from the USGS website (https: / / glovis.usgs.gov /) and employed in this study. In addition, one scene of digital elevation model (DEM) data of ALOS/PALSAR with $12.5 \mathrm{~m}$ spatial resolution was obtained from the NASA website (https://vertex.daac.asf.alaska.edu/\#). The Sentinel-2A image contains 13 spectral bands in the VNIR and SWIR spectral range, with four bands at $10 \mathrm{~m}$, six bands at $20 \mathrm{~m}$, and three atmospheric correction bands at $60 \mathrm{~m}$ spatial resolution [34], as shown in Table 1. The cloud free image was automatically atmospherically corrected and orthorectified using the Sentinel Application Platform (SNAP) software package provided by ESA. After atmospheric correction, all the image bands were cubically resampled to $20 \mathrm{~m}$ spatial resolution and layer stacked to one file. Since bands 1 , 9, and 10 were designed for atmospheric correction, they were excluded from lithological classification in this study.

Table 1. Description of the Sentinel-2A, operational land imager (OLI), and ASTER sensors.

\begin{tabular}{|c|c|c|c|c|c|c|c|c|}
\hline \multicolumn{3}{|c|}{ Sentinel-2A } & \multicolumn{3}{|c|}{ OLI } & \multicolumn{3}{|c|}{ ASTER } \\
\hline Band & $\begin{array}{c}\text { Central } \\
\text { Wavelength (nm) }\end{array}$ & $\begin{array}{c}\text { Spatial } \\
\text { Resolution (m) }\end{array}$ & Band & $\begin{array}{c}\text { Central } \\
\text { Wavelength (nm) }\end{array}$ & $\begin{array}{c}\text { Spatial } \\
\text { Resolution (m) }\end{array}$ & Band & $\begin{array}{c}\text { Central } \\
\text { Wavelength (nm) }\end{array}$ & $\begin{array}{c}\text { Spatial } \\
\text { Resolution (m) }\end{array}$ \\
\hline 1 & 0.4430 & \multirow[t]{2}{*}{60} & 1 & 0.4430 & \multirow{7}{*}{30} & 1 & 0.5560 & \multirow{4}{*}{15} \\
\hline 2 & 0.4900 & & 2 & 0.4826 & & 2 & 0.6610 & \\
\hline 3 & 0.5600 & \multirow[t]{3}{*}{10} & 3 & 0.5613 & & $3 \mathrm{~N}$ & 0.8070 & \\
\hline 4 & 0.6650 & & 4 & 0.6546 & & $3 \mathrm{~B}$ & 0.8070 & \\
\hline 5 & 0.7050 & & 5 & 0.8646 & & 4 & 1.6560 & \multirow{6}{*}{30} \\
\hline 6 & 0.7400 & \multirow[t]{2}{*}{20} & 6 & 1.6090 & & 5 & 2.1670 & \\
\hline 7 & 0.7830 & & 7 & 2.2010 & & 6 & 2.2090 & \\
\hline 8 & 0.8420 & 10 & 8 & 0.5917 & 15 & 7 & 2.2620 & \\
\hline $8 \mathrm{~A}$ & 0.8650 & 20 & & & \multirow{4}{*}{30} & 8 & 2.3360 & \\
\hline 9 & 0.9450 & \multirow{3}{*}{60} & 9 & 1.3730 & & 9 & 2.4000 & \\
\hline 10 & 1.3750 & & \multirow{2}{*}{10} & \multirow{2}{*}{10.9000} & & 10 & 8.2910 & \multirow{5}{*}{90} \\
\hline 11 & 1.6100 & & & & & 11 & 8.6340 & \\
\hline \multirow{3}{*}{12} & & \multirow{3}{*}{20} & & & \multirow[t]{3}{*}{100} & 12 & 9.0750 & \\
\hline & 2.1900 & & 11 & 12.0000 & & 13 & 10.6570 & \\
\hline & & & & & & 14 & 11.3180 & \\
\hline
\end{tabular}

As an advanced multispectral sensor launched onboard Terra spacecraft in December 1999, ASTER covers a broad range of spectral region with 14 spectral bands, including three VNIR bands with $15 \mathrm{~m}$ spatial resolution, six SWIR bands with $30 \mathrm{~m}$ spatial resolution, and five TIR bands with $90 \mathrm{~m}$ spatial resolution. In addition, one more telescope is used to see backward in the near infrared spectral band (Band 3B) for stereoscopic capability [35] (Table 1). The level-1B ASTER data employed in this research were acquired on 14 August 2002. The data without cloud were atmospherically corrected and 
calibrated using the ENVI 5.4 software package as follows. The VNIR and SWIR bands of the ASTER data were cubically resampled to $30 \mathrm{~m}$ spatial resolution, layer stacked to construct a single 9-band file, and atmospherically corrected using the FLAASH (Fast Line of Sight Atmospherics Analysis of Hypercubes) module, to eliminate the effects caused by water vapor and cloud and to convert the digital counts to surface reflectance. A cross-track illumination correction was applied to the ASTER images to remove the effects of energy overspill from band 4 into bands 5 to 9 .

As the latest mission in Landsat series launched by NASA on 11 February 2013, Landsat 8 consists of a two-sensor payload, the OLI, and the TIRS (thermal infrared sensor). The OLI contains two more bands than Landsat 7 (ETM+), including a new deep blue band for coastal/aerosol observation and an SWIR band for cirrus detection (Table 1). In this study, one OLI scene acquired on 5 December 2017, was selected for lithological discrimination. The VNIR and SWIR bands of OLI were layer stacked to form a single file with $30 \mathrm{~m}$ spatial resolution. A radiation correction and an atmospherical correction by FLAASH were successively applied to the OLI/Landat- 8 scene to eliminate the effects caused by atmosphere.

The atmospherically corrected Sentinel-2A, OLI and ASTER imagery was georeferenced to the UTM (Universal Transverse Mercator projection) coordinate system in Zone 47 north, using ground control points chosen from the DEM and high-resolution orthorectified Google Earth imagery. The information about the three multispectral images employed in this study is listed in Table 2 . Although these images were acquired in different seasons, maximum normalized different vegetation index (NDVI) of each image is lower than 0.07 , indicating that the study area is an ideal exposed region with almost no vegetation cover for lithological classification. In addition, there are barely snow or cloud covered regions in the study area, as shown in Table 2. Therefore, there are no vegetation, cloud or snow effects in this study.

Table 2. Multispectral image used in this study.

\begin{tabular}{ccccc}
\hline Data & Acquisition Date & Season & Cloud/Snow (\%) & NDVI \\
\hline OLI & $2017 / 12 / 05$ & Winter & $5.2 / 0.0$ & $<0.01$ \\
ASTER & $2002 / 08 / 14$ & Summer & $0.0 / 0.0$ & $<0.07$ \\
Sentinel-2A & $2017 / 05 / 09$ & Spring & $<1 / 0.0$ & $<0.07$ \\
\hline
\end{tabular}

\subsubsection{Lithological Mapping}

Sentinel-2A data contains higher spectral and spatial resolution in the VNIR to SWIR range than common multispectral data, such as OLI and ASTER data. To find the optimal classifier for the classification assessment of Sentinel-2A data in the Shibanjing ophiolite, five typical machine learning techniques, ANN, $k$-NN, MLC, RFC, and SVM, were applied for lithological mapping.

Different data combinations were designed for the assessment of multispectral data from Sentinel-2A for lithological classification, as listed in Table 3. Firstly, considering DEM data can provide geomorphological and subsurface geological information [36], data integration of Sentinel-2A and a DEM (Sentinel-2A + DEM) were compared with Sentinel-2A data alone for lithological classification, for the purpose of evaluating the importance of DEM data for lithological classification in this study. Secondly, three datasets (OLI + DEM, Sentinel-2A + DEM, and ASTER + DEM) were employed in turn for lithological discrimination, in order to compare the capability of Sentinel-2A for lithological classification with other data. Thirdly, with the band configurations of OLI, Sentinel-2A, and ASTER in the VNIR and SWIR range, the data combinations OLI + ASTER or Sentinel-2A + ASTER are expected to provide more diagnostic spectral features of lithological units than the OLI, ASTER, or Sentinel-2A data alone. Therefore, the OLI + ASTER + DEM and Sentinel-2A + ASTER + DEM datasets were compared for lithological classification. After that, two classification results were compared to evaluate whether OLI could be substituted by Sentinel-2A. Figure 2 illustrates the above process in a simplified sequence flow diagram. 
Table 3. Datasets for lithological mapping in this study.

\begin{tabular}{cccc}
\hline Dataset & Abbreviation & Band Number & Spatial Resolution $(\mathbf{m})$ \\
\hline OLI + DEM & OLI_DEM & 8 & 30 \\
ASTER + DEM & AST_DEM & 10 & 30 \\
Sentinel-2A & S2A & 10 & 20 \\
Sentinel-2A + DEM & S2A_DEM & 11 & 20 \\
OLI + ASTER + DEM & OLI_AST_DEM & 18 & 30 \\
Sentinel-2A + ASTER + DEM & S2A_AST_DEM & 20 & 20 \\
\hline
\end{tabular}

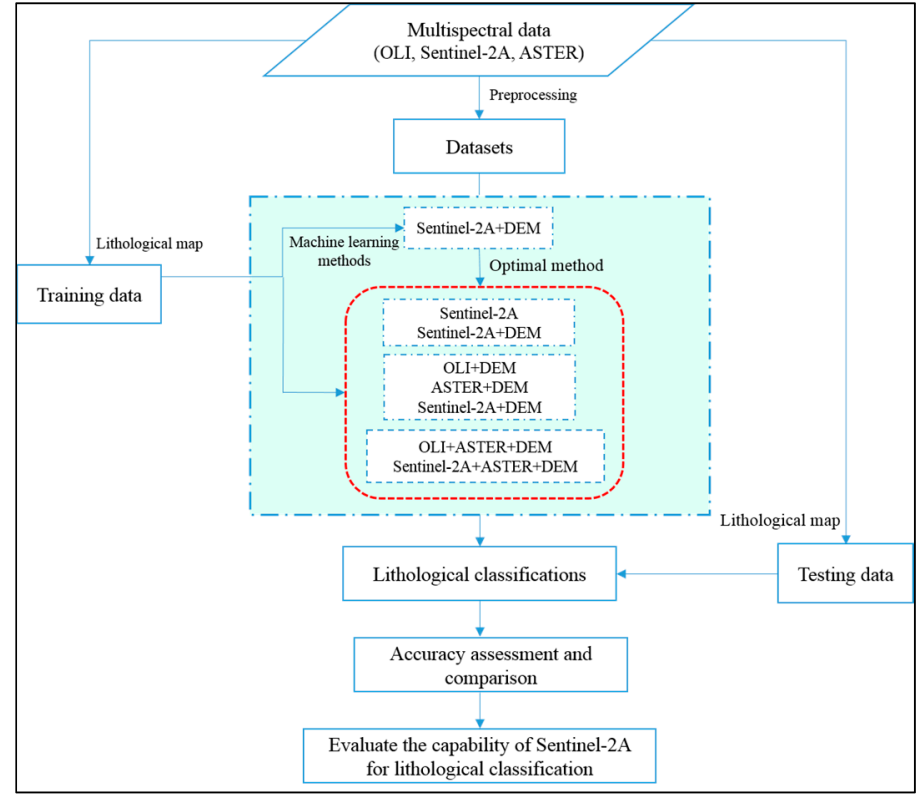

Figure 2. Flowchart of the lithological classification process.

\subsubsection{Training and Testing Samples}

The geological map depicted in Figure 1c was used as a reference for the selection of the training and testing samples. According to the texture characteristics and distributions of the fifteen lithological units (except the quartz, because of its small area) shown in Figure 1c, the training dataset was carefully selected manually by visual interpretation. A total of 12,000 pixels of ASTER data for the fifteen lithological units were selected, which represents approximately $1.9 \%$ of the entire study area. The training datasets were directly utilized by the ANN, $k-N N$, MLC, RFC, and SVM classifiers. Moreover, 1200 ground truth points randomly distributed in the study area were selected as a testing dataset according to the geological map (Figure 1c). The areas, training samples, and testing samples of lithological units are listed in Table 4. 
Table 4. The lithological unit areas, training and testing samples for lithological units.

\begin{tabular}{|c|c|c|c|}
\hline Lithological Unit & Area $\left(\mathrm{km}^{2}\right)$ & Training Sample (Pixels of ASTER) & Testing Sample (Pixels) \\
\hline Alluvium deposits $(\mathrm{Q})$ & 35.62 & 2580 & 306 \\
\hline Schist and metasandstone with marble (Oby) & 4.96 & 491 & 43 \\
\hline Carbonatite with sandstone (Ox.d) & 26.36 & 2504 & 227 \\
\hline Quartz sandstone and siltite (Ox.Q') & 19.25 & 1350 & 164 \\
\hline Basic andesite and tuff (Oh.B) & 15.3 & 960 & 131 \\
\hline Granodiorite (Dgb) & 6.41 & 565 & 52 \\
\hline Quartz diorite (Sqb) & 4.01 & 341 & 34 \\
\hline Basic and ultrabasic rocks $(\Sigma \varepsilon)$ & 1.60 & 184 & 14 \\
\hline Argillaceous matrix (Omss) & 3.93 & 310 & 35 \\
\hline Basalt $(\beta \varepsilon)$ & 7.42 & 834 & 64 \\
\hline Ultramafic rock $(\mathrm{o} \psi \varepsilon)$ & 4.70 & 572 & 40 \\
\hline Marble (mb) & 5.19 & 536 & 45 \\
\hline Dolomite (dol) & 0.32 & 87 & 10 \\
\hline Argillite (mss) & 1.18 & 245 & 10 \\
\hline Limestone (ls) & 2.89 & 441 & 25 \\
\hline
\end{tabular}

\subsection{Machine Learning Methods}

Lithological classification was performed using the five machine learning methods ANN, $k$-NN, MLC, RFC, and SVM. In the following subsections, a brief explanation of the five algorithms is provided.

\subsubsection{Artificial Neural Network}

As a typical machine learning method, the artificial neural network classifier, also known as neural network $(\mathrm{NN})$, is widely employed in pattern recognition and the classification of image data. The NN classifier is an artificial intelligence technique, which attempts to simulate the way in which humans classify patterns, learn tasks, and solve problems [37]. It is made up of a number of simple processing units called nodes or neurons [38]. The nodes are linked by weighted connections according to a specified architecture. There are three layers in the ANN classifier, an input layer, a middle layer (i.e., hidden layer), and an output layer. Each layer of the ANN classifier consists of one or more nodes, which are adjusted through the iterative experiment to obtain the most reasonable output [37].

In this study, a multi-layer feed-forward ANN method was employed with the S2A_DEM dataset for lithological classification in the ENVI 5.4 software. The ANN classifier used a logistic activation function, the training threshold contribution value was 0.9 , the training rate was 0.2 , the training momentum was 0.9 , and the training root mean square (RMS) exit criterion was 0.1 .

\subsection{2. $k$-Nearest Neighbors}

The nonlinear classifier $k$-nearest neighbors $(k-\mathrm{NN})$ is one of the most common machine learning techniques, and a favorite classification algorithm in statistical applications [39]. As a non-parametric algorithm, $k$-NN employs an instance-based leaning algorithm, or a "lazy learning," to find a group of $\mathrm{K}$ samples nearest to unknown samples [40]. $\mathrm{K}$ is a key parameter and plays a significant role in the performance of the $k$-NN classifier $[40,41]$. In this study, the optimal value of $k$ was 5 . The $k$-NN classifier was utilized for lithological classification using the S2A_DEM dataset based on $\mathrm{C}++$ language.

\subsubsection{Maximum Likelihood Classifier}

The maximum likelihood classification (MLC) is one of the most common supervised classifiers in remote sensing [42-44], and was proposed firstly by German mathematician C.F. Gauss in 1821 for normal distribution. This method is based on the hypothesis that the probability density function for each class is multivariate, and an unknown pixel is assigned to a class with the highest probability of belonging [42,45]. As a common multivariate statistical classification method, MLC, is embedded in many image processing software packages, such as PCI, ERDAS, and ENVI. In this study, this classifier was applied to varied datasets for lithological classification using ENVI 5.4 software provided by Exelis Visual Information Solutions in USA. 


\subsubsection{Support Vector Machine}

The support vector machine (SVM) is one of the most widely used supervised machine learning algorithms; it is based on statistical learning theory [25,43,46,47], which was proposed by Vapnik and Chervonenkis in 1963 [48]. The classification mechanism of SVM is to find a hyperplane to classify the given dataset in an $n$-dimensional space. One reasonable choice as the best hyperplane is the one that represents the largest separation between two classes. Target detection using SVM method can be simplified as a dichotomy. In a higher dimensional space, the SVM method needs an optimal linear hyperplane with the maximum margin for separating the given dataset. As the given data in a larger dimensional space can be complex, the kernel function is introduced to address this issue $[49,50]$ :

$$
\mathrm{K}\left(x_{i}, x_{j}\right)=\Phi\left(x_{i}\right)^{T} \Phi\left(x_{j}\right)
$$

As proposed by previous research, there are several common kernel functions for the SVM method, such as linear, polynomial, radial basis function, and sigmoid [41].

Being one of the widely applied multivariate statistical learning methods, SVM has been embedded in many software packages. In this study, the one against one support vector machine (OAO-SVM) classifier accomplished in $\mathrm{C}++$ was employed for lithological mapping. The radial basis function was selected as the kernel type, the penalty parameter was set to 100 , and the gamma in kernel function was the inverse of the band number of the S2A_DEM dataset, namely, 0.091 [51].

\subsubsection{Random Forest Classifier}

The random forest classifier (RFC) has become a favorable and efficient classifier for scientists in many fields, such as geology and ecology [52-54]. This method is a supervised machine learning approach that contains multiple decision trees and combines the predictions from all trees [52]. Each decision tree returns a classification, and a random forest decides which class each observation is attributed to, based on majority rule, that the class that has the most votes across all trees is determined as the final class [55].

To implement the RFC method, two parameters need to be set up: the number of trees, and the number of features in each split [56]. In the present work, the number of trees is 1000, and the number of features in each split is 30. The RFC method was performed in ArcGIS 10.4 software.

\section{Results}

The classification accuracy of the lithological map obtained from each classifier and dataset described above was assessed using the overall accuracy, average accuracy (the average of user's and producer's accuracies), and Kappa coefficient, obtained from the confusion matrix. The overall accuracy is calculated as the total number of correctly classified pixels (diagonal elements of the confusion matrix) divided by the total number of test pixels. The producer's accuracy is the probability that the classifier has correctly labeled an image pixel, and the user's accuracy indicates the probability that the classifier has correctly labeled a pixel into its pre-given class. The Kappa coefficient is a measure of agreement between the classified map and the reference data. The Kappa coefficient is different from the overall accuracy and takes into account the entire contingency matrix, which is designed to measure the consistency of the results [57]. The assessment was to estimate the classification results obtained from different methods and datasets, evaluating the capability of classification techniques for lithological mapping in the study area.

\subsection{Lithological Discrimination Using Machine Learning Methods}

Lithological classification of the S2A_DEM dataset using the different machine learning methods of ANN, $k$-NN, MLC, RFC, and SVM are displayed in Figure 3. The lithological results obtained using $k$-NN show more noise than other results, as illustrated in Figure 3. The mapping results of granodiorite and quartz diorite using $k$-NN are largely misclassified into surrounding lithological units. In addition, 
the dolomite is completely misclassified into basalt by the ANN method, as shown in Figure 3c. The lithological units extracted using the methods of SVM and MLC are more precise than the results obtained from the ANN and SVM techniques, according to the geological map (Figure 1c). However, due to their similar compositions and adjacent positions, it is difficult to distinguish carbonatite with sandstone from quartz sandstone and siltite using these five machine learning methods.

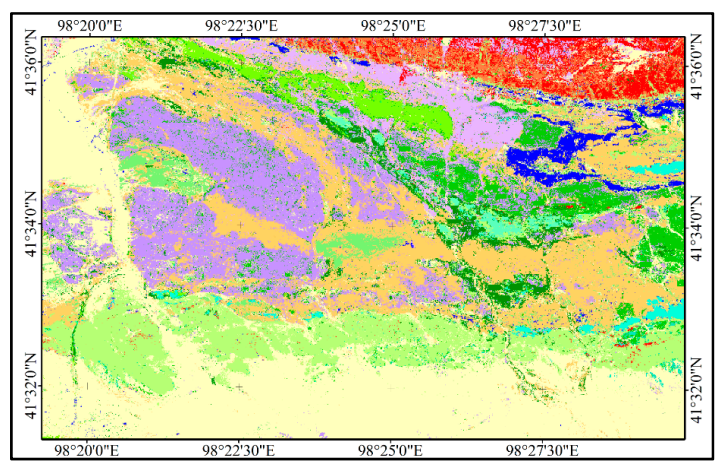

(a)

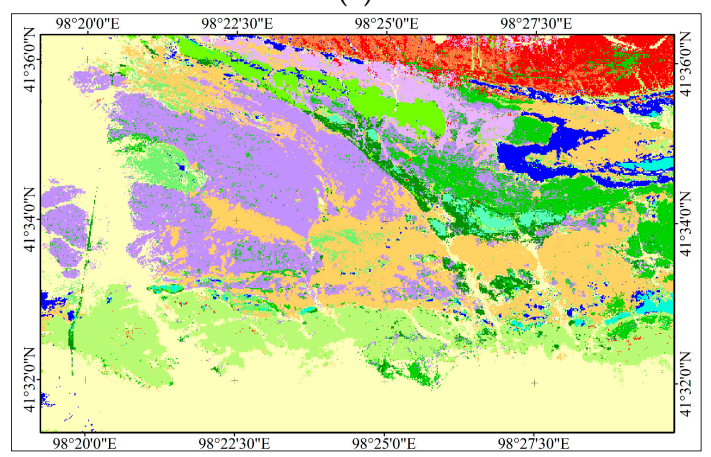

(c)

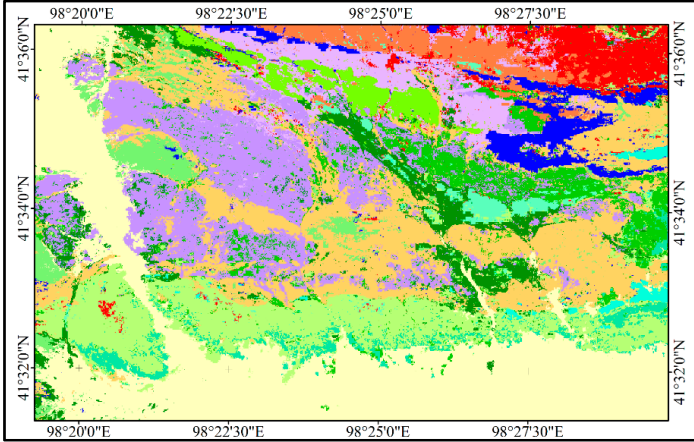

(b)

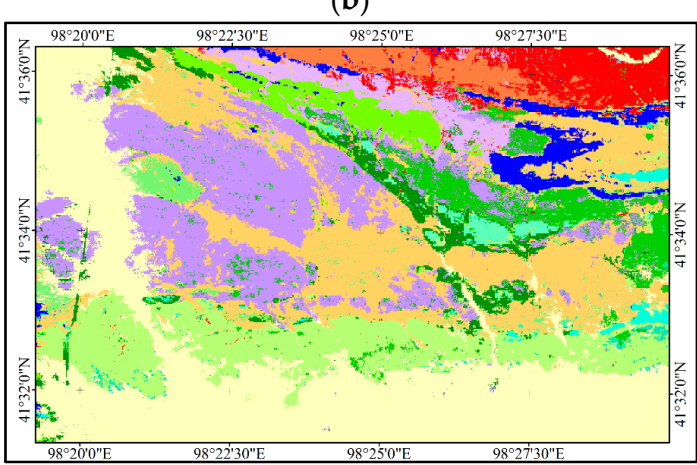

(d)

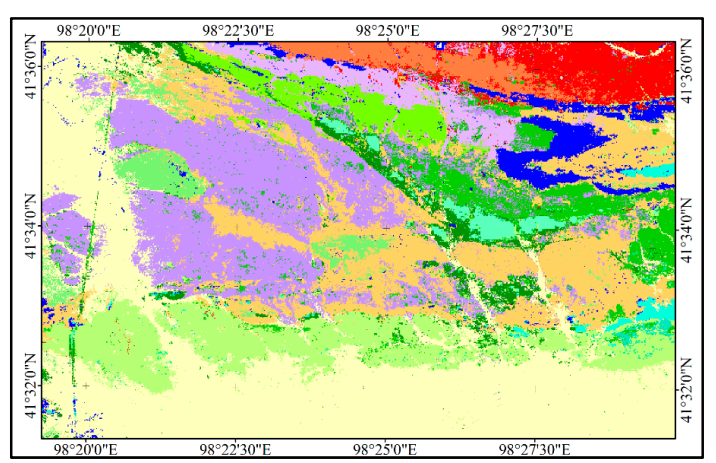

(e)

\begin{tabular}{|l|l|l|l|}
\hline Legend & & Late Devonian-Granodiorite & Cambrian-Ultramafic rock \\
Quaternary-Alluvium deposits & & Marble \\
Late Ordovician-Schist and metasandstone with marble & Middle Silurian-Quartz-diorite & Dolomite \\
Late Ordovician-Carbonatite with sandstone & Cambrian-Basic and ultrabasic rocks & Argillite \\
Late Ordivician-Quartz-sandstone and siltite & Ordovian-Argillaceous matrix & Limestone \\
\hline Middle Ordovician-Basaltic andesite and tuff & Cambrian-Basalt & \\
\hline
\end{tabular}

Figure 3. Lithological classification of the S2A_DEM dataset using machine learning methods. (a) $k$-nearest neighbor $(k-\mathrm{NN})$; (b) random forest classifier (RFC); (c) artificial neural network (ANN); (d) support vector machine (SVM); (e) maximum likelihood classification (MLC).

The classification accuracies and Kappa coefficients of mapping results of S2A_DEM using different machine learning methods are displayed in Figure 4 . The classification using the $k$-NN 
method shows the lowest accuracies and Kappa coefficient in Figure 4, in keeping with Figure 3. The average accuracies of most lithological units obtained by $k-\mathrm{NN}$ are lower than $70 \%$. The ANN and RFC methods show similar overall accuracies and Kappa coefficients, which are lower than those of the MLC and SVM techniques. Moreover, the classification of dolomite obtained by the ANN method is $0 \%$, and the accuracies of more than 10 lithological units extracted by ANN and RFC were lower than $70 \%$, indicating that these two methods (ANN and RFC) are not suitable for lithological discrimination in the Shibanjing ophiolite complex. As shown in Figures 3 and 4, the two statistical learning methods of SVM and MLC yielded quite good performances in lithological classification. Due to its slightly higher overall accuracy, the MLC approach was employed to evaluate the potential of Sentinel-2A imagery to discriminate lithological units in the following research.

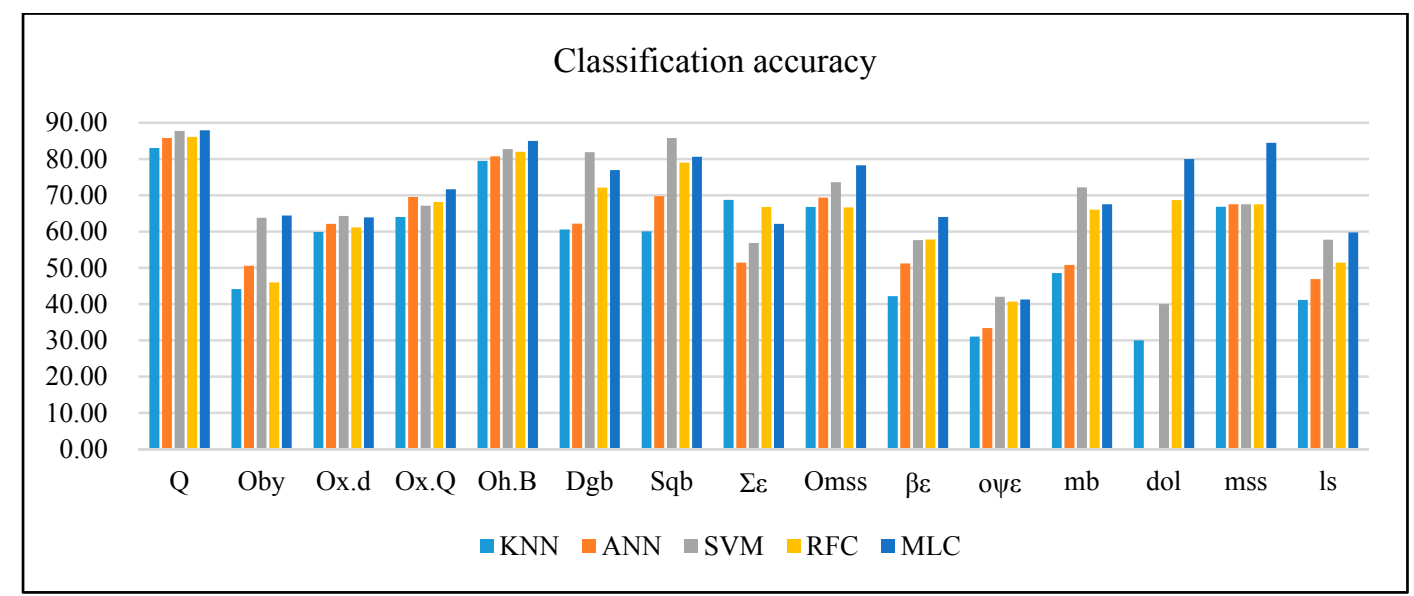

(a)

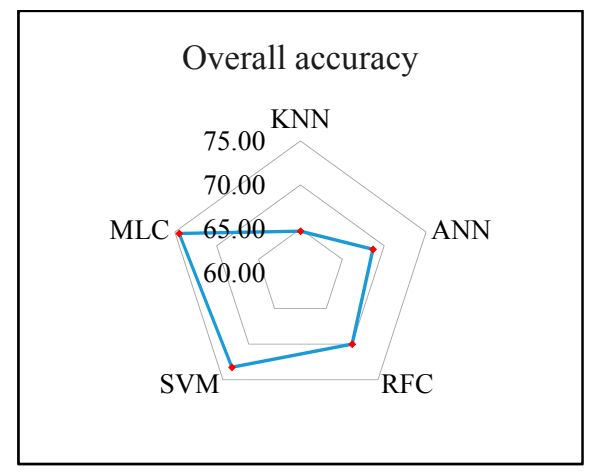

(b)

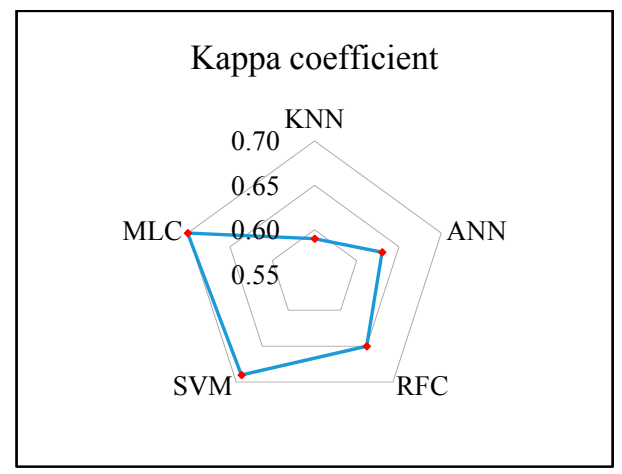

(c)

Figure 4. (a) The lithological classification accuracies of each class; (b) overall accuracies; and (c) Kappa coefficient of the S2A_DEM dataset using different machine learning methods.

\subsection{Lithological Discrimination Using S2A and S2A_DEM Datasets}

The classification results of two datasets, S2A and S2A_DEM, using MLC technique, are displayed in Figure 5. As shown in Figure 5a, there is more noise for the S2A dataset in the lithological classification. Affected by the extensive weathering and complex terrain, the alluvium deposits were largely misclassified into surrounding lithological units. Moreover, with the influence of topography, other lithological units are also misclassified into the alluvium deposits, as displayed in Figure 5a. Figure $5 \mathrm{~b}$ is the partial magnification of the classification of Sentinel-2A, which clearly shows the misclassified region. By combining DEM data with the Sentinel-2A image, the mapping results are dramatically improved, as shown in Figure 5c. The alluvium deposits are effectively differentiated from surrounding lithological units, and most noise is eliminated. 


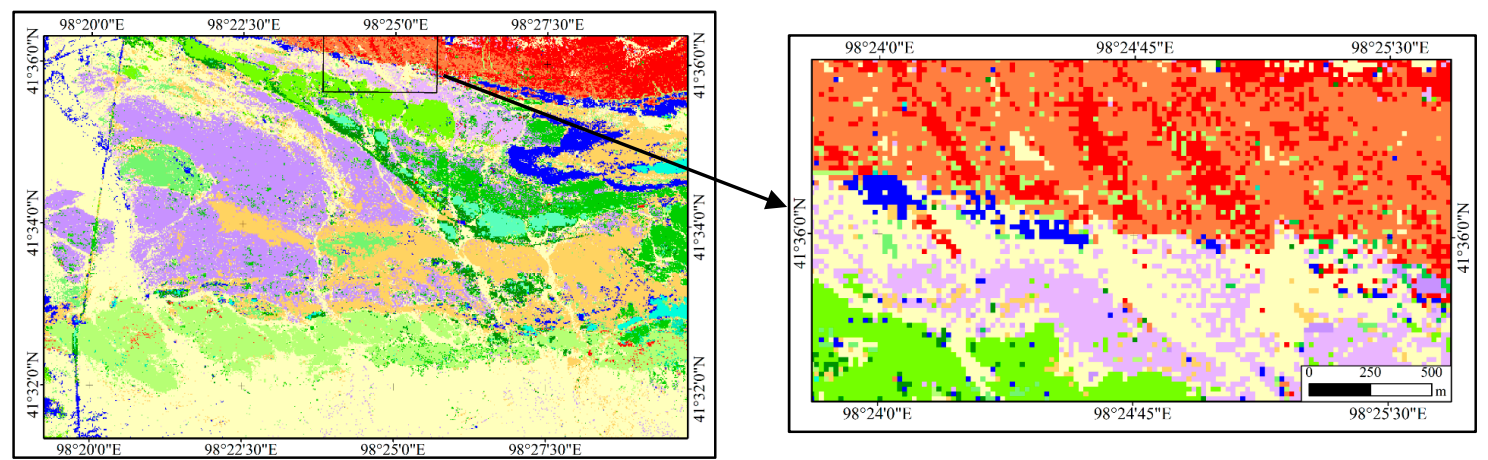

(a)

(b)

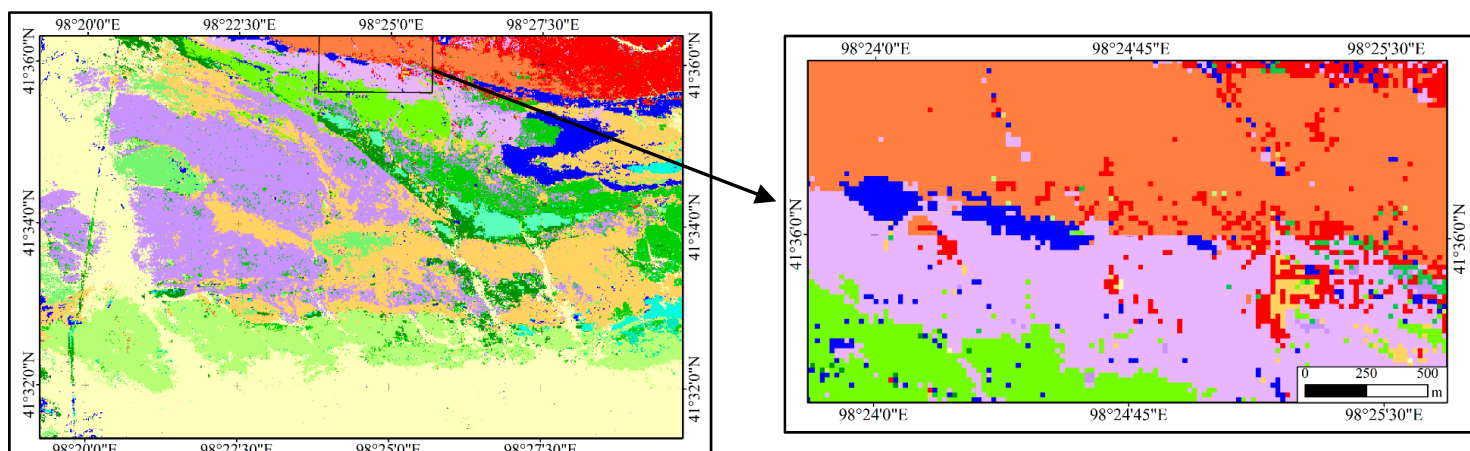

(c)

(d)

\begin{tabular}{|c|c|c|}
\hline \multicolumn{3}{|l|}{ Legend } \\
\hline Quaternary-Alluvium deposits & Late Devonian-Granodiorite & Cambrian-Ultramafic rock \\
\hline Late Ordovician-Schist and metasandstone with marble & Middle Silurian-Quartz-diorite & Marble \\
\hline Late Ordovician-Carbonatite with sandstone & Cambrian-Basic and ultrabasic rocks & Dolomite \\
\hline Late Ordivician-Quartz-sandstone and siltite & Ordovian-Argillaceous matrix & Argillite \\
\hline Middle Ordovician-Basaltic andesite and tuff & Cambrian-Basalt & Limestone \\
\hline
\end{tabular}

Figure 5. Lithological classification of different datasets using the MLC method. (a) S2A, (b) partial magnification of (a), (c) S2A_DEM, and (d) partial magnification of (c).

Figure 6 shows the average accuracies of each lithological unit based on the S2A and S2A_DEM datasets using the MLC technique. As with Figure 5, the classification accuracies of the S2A_DEM dataset are all higher than those of the single Sentinel-2A data, demonstrating the significance of DEM data for lithological mapping. The overall accuracy of the classification using the S2A_DEM dataset is $74.5 \%$, which is $8.25 \%$ higher than that of the S2A dataset, as shown in Figure 7.

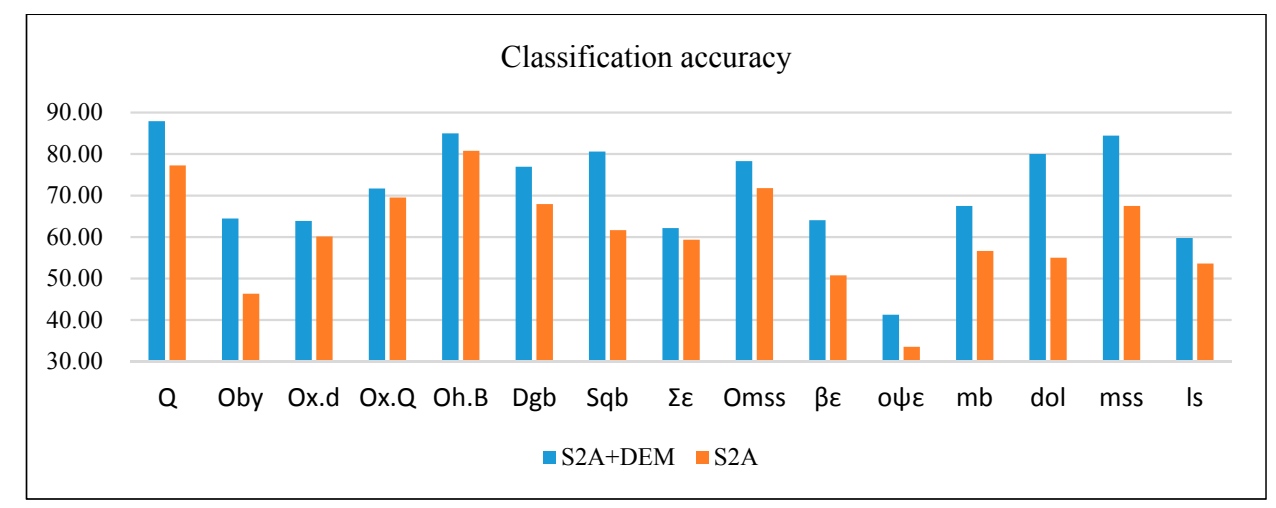

Figure 6. The lithological classification accuracies of the S2A and S2A_DEM datasets using the MLC method. 


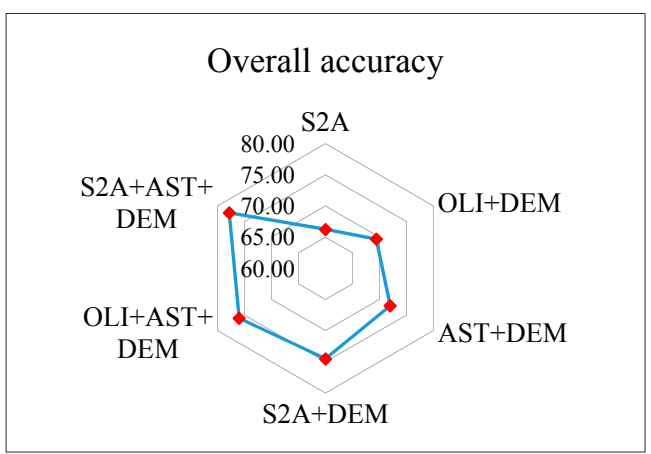

(a)

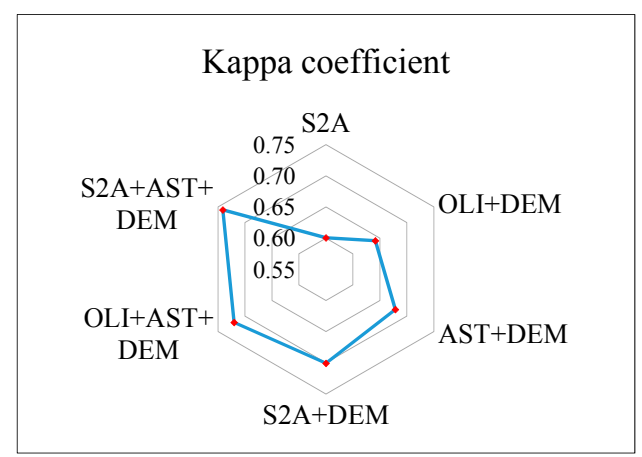

(b)

Figure 7. The overall accuracies and Kappa coefficients of datasets using the MLC method.

\subsection{Lithological Discrimination Using OLI_DEM, AST_DEM and S2A_DEM Datasets}

Lithological classifications of the OLI_DEM and AST_DEM datasets using the MLC method are shown in Figure 8a,b, respectively. In comparison with the lithological results of the S2A_DEM dataset (Figure 3e) and the geological map (Figure 1c), Sentinel-2A shows a better capability for lithological discrimination than ASTER and OLI, especially in identifying basaltic andesite and tuff, and argillaceous matrix.

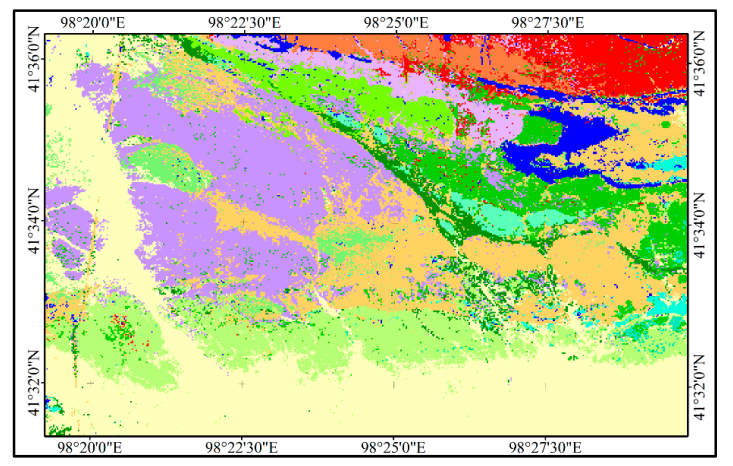

(a)

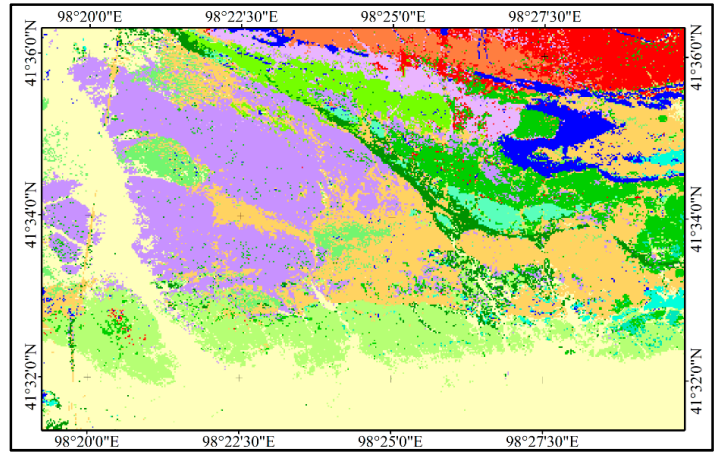

(b)

\begin{tabular}{|l|l|l|l|}
\hline $\begin{array}{l}\text { Legend } \\
\text { Quaternary-Alluvium deposits }\end{array}$ & Late Devonian-Granodiorite & Cambrian-Ultramafic rock \\
Late Ordovician-Schist and metasandstone with marble & Middle Silurian-Quartz-diorite & Marble \\
Late Ordovician-Carbonatite with sandstone & Cambrian-Basic and ultrabasic rocks & Dolomite \\
\hline Late Ordivician-Quartz-sandstone and siltite & Ordovian-Argillaceous matrix & Argillite \\
Middle Ordovician-Basaltic andesite and tuff & Cambrian-Basalt & Limestone \\
\hline
\end{tabular}

Figure 8. MLC-generated lithological classifications of two different datasets. (a) OLI_DEM; and (b) AST_DEM.

As displayed in Figure 9, the OLI_DEM dataset shows the worst capability for lithological classification among the three datasets. The overall accuracies of the OLI_DEM dataset $(69.42 \%)$ is also lower than those of the AST_DEM (72.0\%) and S2A_DEM (74.5\%), as shown in Figure 7. As illustrated in Figures 6-8, the multispectral Sentinel-2A shows better capability for lithological classification than OLI and ASTER in the Shibanjing ophiolite complex. 


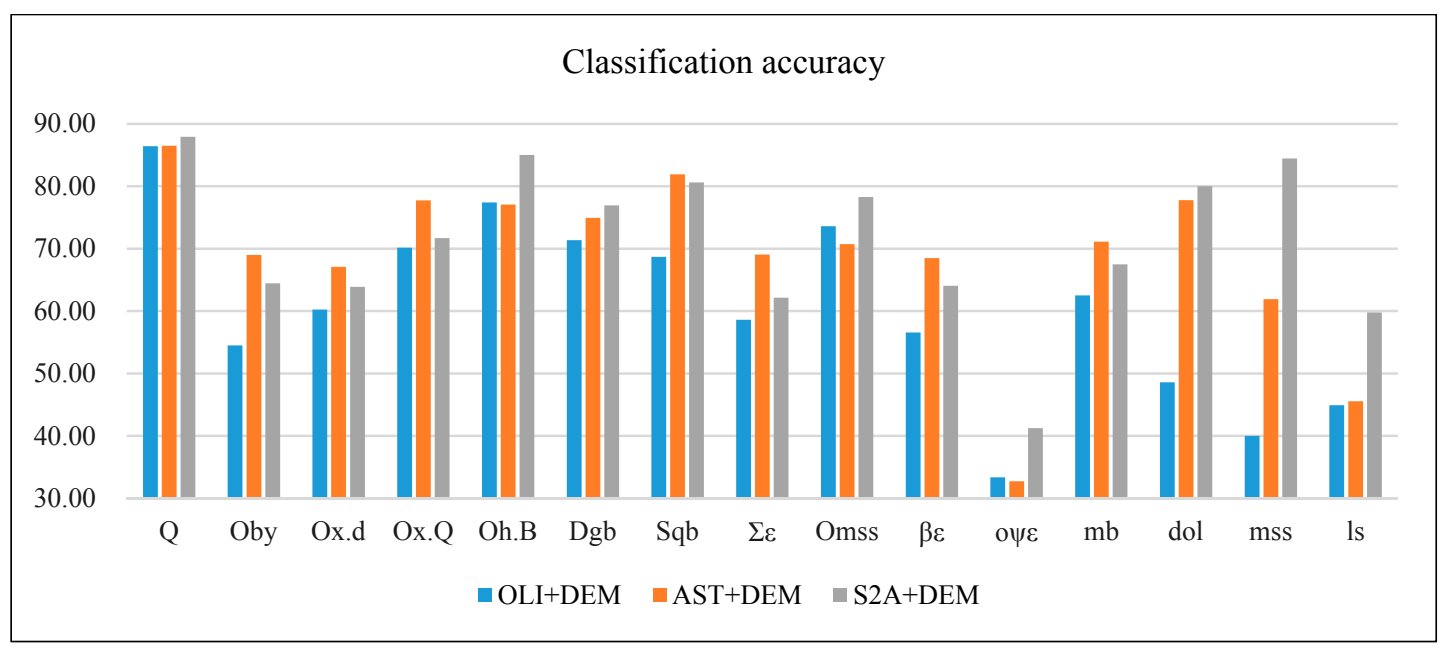

Figure 9. The classification accuracies of datasets of OLI + DEM and AST + DEM using the MLC method.

\subsection{Lithological Discrimination Using OLI_AST_DEM and S2A_AST_DEM Datasets}

The OLI_AST_DEM and S2A_AST_DEM datasets were used for classification using the MLC method, and the results are shown in Figure 10. The results using the S2A_AST_DEM dataset, which classified the granodiorite, quartz diorite (Figure 10c-e), and basalt (Figure 10f-h) better, show a higher consistency with the geological map than the results obtained from the OLI_AST_DEM dataset. In addition, the classification results obtained from dataset S2A_AST_DEM show clearer boundaries between different rocks because of the higher spatial resolution of dataset S2A_AST_DEM. Moreover, there are fewer misclassified cases in the classification map of the S2A_AST_DEM dataset. The alluvium deposits were ideally recognized in Figure 10b.

The average accuracies of lithological classification by the data combinations of OLI + ASTER + DEM and Sentinel-2A + ASTER + DEM using the MLC method are displayed in Figure 11. Most of the lithological units obtained from the data combination of Sentinel-2A + ASTER + DEM have higher accuracies than those extracted from the OLI + ASTER + DEM dataset. The overall accuracy of lithological classification using the S2A_AST_DEM dataset is $77.83 \%$, which is $1.83 \%$ higher than that of the OLI_AST_DEM dataset, and higher than the accuracies without incorporating ASTER dataset, as shown in Figure 7. The comparison between different datasets using the MLC method indicates that the data combination of Sentinel-2A + ASTER + DEM shows the greatest potential to classify the lithological units in the Shibanjing ophiolite complex. 


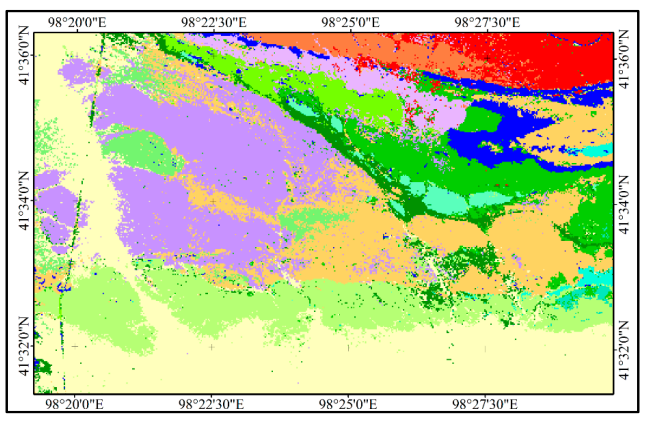

(a)

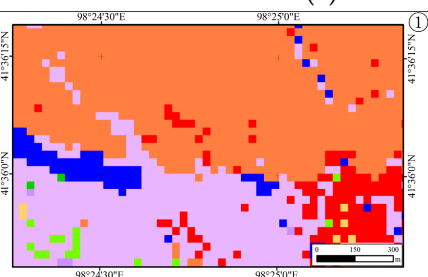

(c)

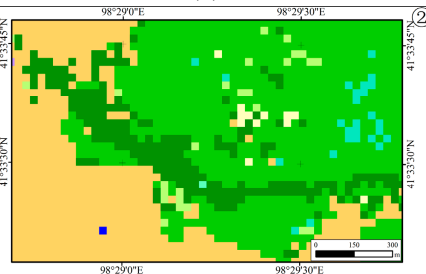

(f)

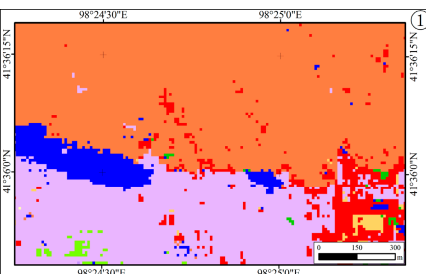

(d)

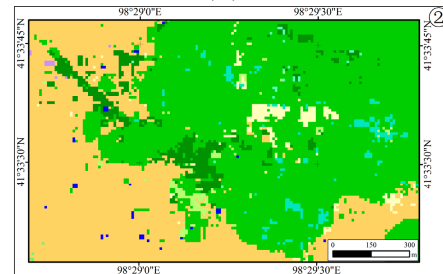

(g)

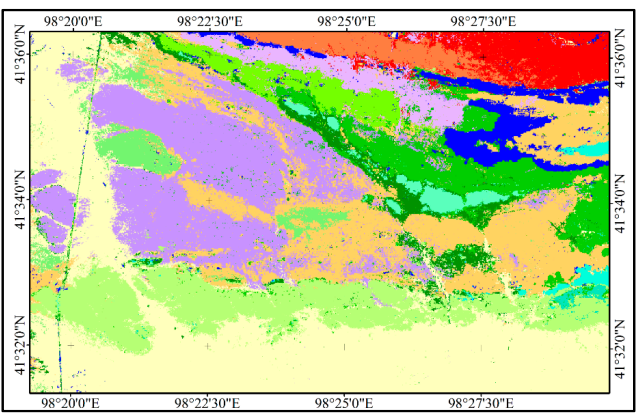

(b)

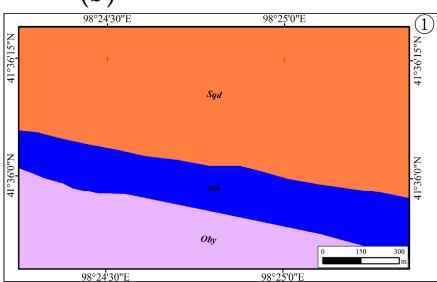

(e)

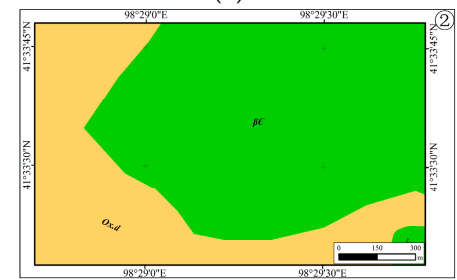

(h)

\begin{tabular}{|l|l|l|}
\hline Legend & Late Devonian-Granodiorite & Cambrian-Ultramafic rock \\
Quaternary-Alluvium deposits & Middle Silurian-Quartz-diorite & Marble \\
Late Ordovician-Schist and metasandstone with marble & Cambrian-Basic and ultrabasic rocks & Dolomite \\
Late Ordovician-Carbonatite with sandstone & Ordovian-Argillaceous matrix & Argillite \\
Late Ordivician-Quartz-sandstone and siltite & Cambrian-Basalt & Limestone \\
Middle Ordovician-Basaltic andesite and tuff & Cam & \\
\hline
\end{tabular}

Figure 10. Lithological classification of three different datasets using MLC. (a) The classification of OLI_AST_DEM; (b) the classification of S2A_AST_DEM; (c) partial magnification of quartz diorite in (a); (d) partial magnification of quartz diorite in (b); (e) partial magnification of quartz diorite in geological map; (f) partial magnification of basalt in (a); (g) partial magnification of basalt in (b); (h) partial magnification of basalt in geological map.

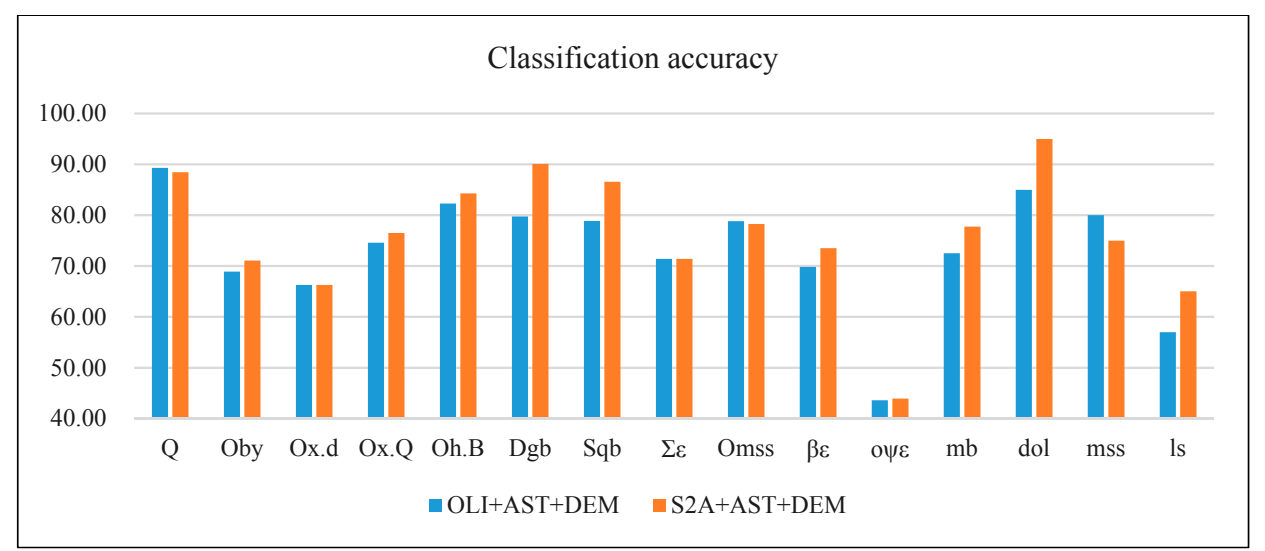

Figure 11. The classification accuracies of the OLI + AST + DEM and S2A + AST + DEM datasets using the MLC method. 


\section{Discussion}

The machine learning methods are evaluated for lithological classification in the barely vegetation covered and well-exposed ophiolite complex using the lithological mapping results. It is shown that the MLC method yielded similar results to the SVM technique, better than the supervised $k$-NN, ANN, and RFC methods, which matches the geological map well in most of the lithological units in the study area, except for the quartz vein. However, although the supervised technique $k$-NN has been one of the foremost techniques for classification in many fields $[41,58]$, the lithological classification using the $k$-NN method in the Shibanjing ophiolite complex shows somewhat lower consistency with the geological map, especially in quartz diorite, basic, and ultrabasic rock, ultramafic rock, and limestone. The classified results using the $k$-NN method were greatly affected by the terrain, making it difficult to differentiate alluvium deposits from other lithological units. SVM has a lower requirement for the distribution of data than MLC, whereas the input data of MLC need to satisfy the assumption of normality. With the normally distributed samples in the Shibanjing ophiolite complex, the classification using MLC shows a higher overall accuracy than that of SVM.

In addition, an analysis of variance was conducted to compare the effect of machine learning methods for lithological classification using the non-parametric McNemar test. The McNemar test is a chi-squared statistic with 1 degree of freedom, which is used on nominal data to determine whether the row and column marginal frequencies are equal [59]. The McNemar test is compared to the critical value at a particular significance level, e.g., $5 \%$, to test if there are significant differences in the expected values of two results [60]. The MLC method shows statistically significant differences with respect to $k$-NN, ANN, and RFC techniques at the 95\% confidence interval, as shown in Table 5. MLC and SVM have the similar performance for lithological classification, and there was no substantial difference in their performances at the 95\% confidence interval. Therefore, the MLC and SVM methods were proven to be more capable for lithological mapping in the Shibanjing ophiolite complex than the other three techniques. However, the optimal classifier for image classification may be different in other study areas.

Table 5. McNemar's test for machine learning methods $\left(x^{2}=3.841, p=0.05\right)$.

\begin{tabular}{cccccc}
\hline & MLC & SVM & RFC & ANN & $k$-NN \\
\hline MLC & $\backslash$ & Not significant & Significant & Significant & Significant \\
SVM & 3.814 & $\backslash$ & Significant & Significant & Significant \\
RFC & 31.696 & 20.280 & $\backslash$ & Not significant & Significant \\
ANN & 70.000 & 38.291 & 2.510 & $\backslash$ & Significant \\
$k$-NN & 63.751 & 52.267 & 22.112 & 16.005 & $\backslash$ \\
\hline
\end{tabular}

Different rock units have different susceptibilities to weathering, because of their diverse mineralogical composition, texture, age and rate of erosion, which lead to different topographic expressions in the field [22]. For example, alluvium deposits generally form flatlands, whereas granitic plutons form high hills, because of their high resistance to erosion. The DEM data, obtained from satellite, could be used to quantify the topographical expressions of rock units. In this research, the overall accuracy of mapping results obtained from the S2A_DEM dataset is 74.5\%, approximately $8 \%$ higher than the results obtained from the Sentinel-2A image alone. The dramatic improvements of classification obtained by incorporating DEM data are mainly focused on schist and metasandstone with marble $(18.11 \%)$, quartz diorite $(18.95 \%)$, dolomite $(25 \%)$, and argillite $(16.94 \%)$, as displayed in Figures 4 and 5 .

Figure 12 reveals the terrain characteristics of the study area. From a geomorphological point of view, the alluvium deposits show a significant difference from the surrounding lithological units, which makes a great improvement in classification, as displayed in Figures 4 and 5. Similarly, the significantly increased accuracies of quartz diorite, basalt and marble are all due to the input of DEM data. Because of the small outcrops of dolomite, argillite and limestone in the study area, 
a small improvement in classification could lead to a significant increase in accuracy. Therefore, the DEM data play an essential role in lithological classification as it quantifies topographic features, which is a good indicator of rock types.

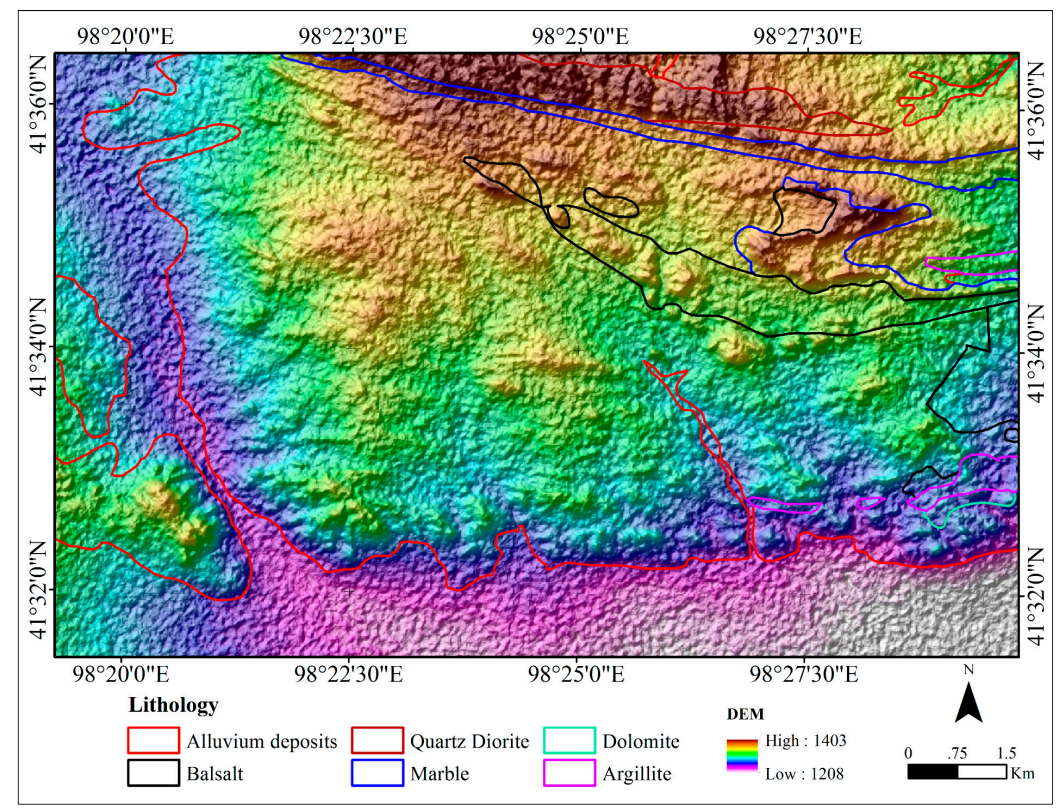

Figure 12. The topographic map of the Shibanjing ophiolite obtained from DEM.

By comparing the three different datasets OLI_DEM, AST_DEM, and S2A_DEM for lithological classification, the capability of Sentinel-2A for lithological mapping in the semi-arid and arid regions, such as the Shibanjing ophiolite complex, was evaluated. As part of the data continuity of Landsat and SPOT, Sentinel-2A has higher spatial and spectral resolution in VNIR range than ASTER and OLI, especially in the ferric iron $\left(\mathrm{Fe}^{3+}\right)$ diagnostic absorption features, approximately 0.65 and $0.87 \mu \mathrm{m}$ [61], which makes it more sensitive for ultramafic rocks and andesite in the present study. As shown in the classification accuracies in Figure 8, the accuracy of ultramafic rocks in the ophiolite complex obtained from the S2A_DEM dataset is approximately 7.9\% and 8.5\% higher than those of OLI and ASTER, respectively. Moreover, due to the lower spectral resolution of OLI compared to Sentinel-2A in the VNIR and SWIR range, the fifteen lithological accuracies of the OLI_DEM dataset are all lower than those of the S2A_DEM dataset.

However, with the higher spatial resolution of ASTER compared to Sentinel-2A in the SWIR range, some of the classification accuracies of lithological units obtained from the AST_DEM dataset are higher than those extracted from the S2A_DEM dataset. For example, with the diagnostic spectral features of calcite in the ASTER band 8 [62,63], the classified marble using ASTER shows a higher accuracy than that of Sentinel-2A. In addition, with the significant SWIR absorption features of silicate minerals in ASTER bandpasses [64], ASTER has a better capability for classifying sandstones and quartz diorite than Sentinel-2A, as illustrated in Figures 4 and 5.

Through the comparison of lithological classification using different multispectral data, it can be concluded that, due to its higher bandpasses in the VNIR and SWIR range, the multispectral Sentinel-2A has a greater potential for lithological mapping than OLI. In addition, because of their respective higher spectral resolutions in VNIR and SWIR, Sentinel-2A shows a better capability for mapping ferric rocks, whereas ASTER has a better ability to classify rocks that contain carbonate, hydrate, and hydroxyl-bearing sulfate, silicate, and other minerals that possess SWIR absorption features. In the present research, due to the large outcrop of alluvium deposits and ophiolitic rocks, the overall accuracy of the S2A_DEM dataset is $74.5 \%, 2.5 \%$ higher than that of the AST_DEM dataset. 
The McNemar's test for all datasets employed in this study were listed in Table 6. The S2A_DEM dataset shows statistically significant differences with respect to the OLI_DEM and AST_DEM datasets in the ophiolite complex, demonstrating the capability of Sentinel-2A for lithological classification. In addition, the data combination S2A_AST_DEM show statistically significant differences with the five other datasets, indicating the best capability of S2A_AST_DEM dataset for lithological classification in the study area.

Table 6. McNemar's test for datasets $\left(x^{2}=3.841, p=0.05\right)$.

\begin{tabular}{ccccccc}
\hline & S2A & OLI_DEM & AST_DEM & S2A_DEM & OLI_AST_DEM & S2A_AST_DEM \\
\hline S2A & $\backslash$ & $\mathrm{S}$ & $\mathrm{S}$ & $\mathrm{S}$ & $\mathrm{S}$ & $\mathrm{S}$ \\
OLI_DEM & 22.563 & $\backslash$ & $\mathrm{S}$ & $\mathrm{S}$ & $\mathrm{S}$ & $\mathrm{S}$ \\
AST_DEM & 21.740 & 5.085 & $\backslash$ & $\mathrm{S}$ & $\mathrm{S}$ & $\mathrm{S}$ \\
S2A_DEM & 99.000 & 61.000 & 5.114 & $\backslash$ & $\mathrm{S}$ & $\mathrm{S}$ \\
OLI_AST_DEM & 117.000 & 79.000 & 14.222 & 8.100 & $\backslash$ & $\mathrm{S}$ \\
S2A_AST_DEM & 137.028 & 101.000 & 28.824 & 29.630 & 16.133 & $\backslash$ \\
\hline
\end{tabular}

Considering their respective spectral advantages in the VNIR and SWIR ranges, the integration of OLI or Sentinel-2A with ASTER could provide more comprehensive spectral information for lithological classification. The overall accuracy obtained from these two data combinations is the highest, and the classification has the best performance among all the cases. Moreover, the contrast between the mapping results extracted from these two data combinations indicated that Sentinel-2A could replace OLI, which, combined with ASTER, could provide better capability for lithological classification result in this study area.

The overall accuracies of lithological classification using different methods and datasets from last few years are listed in Table 7. They were compared with the overall accuracies of lithological classification in the present research to assess the performance of data combinations for lithological discrimination in the Shibanjing ophiolite complex. The overall accuracies for lithological classification, listed in Table 7 , range from $73 \%$ to more than $95 \%$. However, the great accuracies were generally obtained from a dataset that had been processed by conventional image processing methods, instead of the original dataset. The conventional image processing methods, such as principal component analysis (PCA) and minimum noise fraction (MNF), could increase the quality of the input dataset to provide better classification results than the original data [65]. For the classification obtained from the original dataset, the overall accuracies range between $76 \%$ and $95 \%$, and half of these were extracted from hyperspectral imagery. The overall accuracy obtained from S2A_AST_DEM is 77.83\%, lower than those from [66] and [51]. Nevertheless, the number of lithological classes in this study is fifteen, which is more than the classes from [66] (seven classes) and [51] (nine classes).

Multispectral and hyperspectral data are widely utilized for lithological discrimination and classification. However, due to the high cost and complex processing, it is more difficult to obtain appropriate hyperspectral data for geological investigation. In addition, it is more common to combine multispectral data with DEM, textual, and feature data for lithological classification. The research using the combination of two types of multispectral imagery for lithological classification has rarely appeared in previous studies.

The objective of this study was to evaluate the potential of the new multispectral data from Sentinel-2A for lithological classification in semi-arid and arid regions, such as the Shibanjing ophiolite complex in Inner Mongolia, China. The machine learning methods, utilized in the study, are all conventional classifiers and just tools for data assessment. In addition, with the different abilities to recognize lithological units of ASTER and Sentinel-2A data, it may lead to different results when testing on another area. 
Table 7. Results from lithological classification using different remote sensing datasets and classifiers from the last few years.

\begin{tabular}{|c|c|c|c|c|c|c|c|c|}
\hline Data & Ancillary Data & Sensor Type & Band Layers & Method & $\begin{array}{c}\text { Class } \\
\text { Number }\end{array}$ & $\begin{array}{c}\text { Overall } \\
\text { Accuracy }\end{array}$ & $\begin{array}{c}\text { Original Image } \\
(\mathrm{Y} / \mathrm{N})\end{array}$ & Reference \\
\hline $\mathrm{TM}$ & $\begin{array}{l}\text { GLCM }^{1} \text {-based } \\
\text { Textural feature }\end{array}$ & Multi $^{2}$ & 9 & MLC; KBS $^{3}$ & 16 & $83.2 \%$ & $\mathrm{~N}$ & [23] \\
\hline $\mathrm{TM}$ & & Multi & 4 & ANN & 7 & $87.7 \%$ & $\mathrm{Y}$ & [66] \\
\hline ASTER & DEM & Multi & 33 & SVM & 7 & $92.34 \%$ & $\mathrm{~N}$ & [22] \\
\hline ASTER & $\begin{array}{c}\text { Geomorphic } \\
\text { feature, texture }\end{array}$ & Multi & 21 & SVM & 9 & $79.3 \%$ & Y & [51] \\
\hline Hyperion & & Hyper ${ }^{4}$ & 158 & SAM & 9 & $76.12 \%$ & $\mathrm{Y}$ & [1] \\
\hline LiDAR & ATM $^{5}$ & LiDAR/Multi & 5 & OBIA $^{6}$ & 4 & $73.5 \%$ & $\mathrm{~N}$ & [67] \\
\hline OLI & $\begin{array}{c}\text { Textural } \\
\text { vectors } / \mathrm{J}-\mathrm{M}^{7} \\
\text { distance }\end{array}$ & Multi & 14 & SVM & 4 & $83.73 \%$ & $\mathrm{~N}$ & [68] \\
\hline ASTER & & Multi & 37 & RFC & 8 & $81.52 \%$ & $\mathrm{~N}$ & [2] \\
\hline ASTER & & Multi & 9 & ANN & 10 & $79.8 \%$ & $\mathrm{~N}$ & [65] \\
\hline Hymap & & Hyper & 126 & $\begin{array}{l}\text { Spectral } \\
\text { feature } \\
\text { extraction; } \\
\text { SVM }\end{array}$ & 6 & $>70 \%$ & $\mathrm{~N}$ & [25] \\
\hline HyspIRI $^{8}$ & & Hyper & 202 & GA-SAM $^{9}$ & 15 & $>95 \%$ & $\mathrm{Y}$ & [69] \\
\hline
\end{tabular}

\section{Conclusions}

Through a comprehensive comparison, the machine learning method MLC was chosen as the classifier for the assessment of multispectral Sentinel-2A data for lithological mapping in the Shibanjing ophiolite complex in the Beishan orogenic belt, Inner Mongolia, China. Various data combinations of OLI, ASTER, Sentinel-2A, and DEM data were compared to evaluate the capability of Sentinel-2A for lithological classification using the MLC method. According to the comparisons and discussions, the following points are concluded:

(1) The MLC and SVM machine learning methods are equally applicable for lithological classification in the Shibanjing ophiolite complex and better than the techniques of $k-\mathrm{NN}, \mathrm{ANN}$, and RFC using Sentinel-2A data.

(2) Multispectral Sentinel-2A data have greater potential for lithological classification than ASTER and OLI in this research, and the DEM data also play a significant role in lithological mapping.

(3) OLI could be substituted by Sentinel-2A, which when combined with ASTER, exhibits better performance in lithological classification in semi-arid and arid regions, such as the Shibanjing ophiolite complex.

Lithological classification is an important application in geological remote sensing, and the multispectral data Sentinel-2A is demonstrated to be efficient for lithological discrimination. In our future research, we plan to use image processing methods (e.g., PCA, MNF) and morphometric variables (e.g., slope, curvature, roughness) to improve the lithological classification. In addition, to expand the applicability of classification in geological investigation, we plan to study the requirements for accurate lithological classification using optical imagery in covered regions (e.g., vegetation or regolith covers).

Acknowledgments: This research was jointed supported by "the National Science and Technology Support Program of China (2015BAB05B05-02)" and "the Mineral Geological Survey of Heiyingshan area in Inner Mongolia (DD20160040)". The authors are grateful to the United States Geological Survey (USGS) (https://glovis.usgs. gov/), European Space Agency (ESA) and the NASA (https:/ / vertex.daac.asf.alaska.edu/\#) for providing OLI, Sentinel-2A, ASTER and ALOS/PALSAR DEM data. 
Author Contributions: Wenyan Ge, Qiuming Cheng, Linhai Jing and Yunwei Tang conceived and designed the experiments; Yunwei Tang and Linhai Jing wrote the classifiers in C++ language; Wenyan Ge and Chunsheng Gao did the lithological mapping experiments; Qiuming Cheng and Wenyan Ge analyzed the results; Wenyan Ge wrote the paper.

Conflicts of Interest: The authors declare no conflict of interest.

\section{References}

1. Zhang, X.; Li, P. Lithological mapping from hyperspectral data by improved use of spectral angle mapper. Int. J. Appl. Earth Obs. Geoinf. 2014, 31, 95-109. [CrossRef]

2. Masoumi, F.; Eslamkish, T.; Abkar, A.A.; Honarmand, M.; Harris, J.R. Integration of spectral, thermal, and textural features of ASTER data using random forests classification for lithological mapping. J. Afr. Earth Sci. 2017, 129, 445-457. [CrossRef]

3. Gad, S.; Kusky, T. Lithological mapping in the eastern desert of egypt, the barramiya area, using Landsat Thematic Mapper (TM). J. Afr. Earth Sci. 2006, 44, 196-202. [CrossRef]

4. Gad, S.; Kusky, T. ASTER spectral ratioing for lithological mapping in the Arabian-Nubian shield, the Neoproterozoic wadi kid area, Sinai, Egypt. Gondwana Res. 2007, 11, 326-335. [CrossRef]

5. Mars, J.L. Hydrothermal alteration maps of the central and southern basin and range province of the United States compiled from Advanced Spaceborne Thermal Emission and Reflection Radiometer (ASTER) data. Cancer Genet. 2013, 208, 364.

6. Asl, R.A.; Afzal, P.; Adib, A.; Yasrebi, A.B. Application of multifractal modeling for the identification of alteration zones and major faults based on ETM+ multispectral data. Arabian J. Geosci. 2015, 8, 2997-3006. [CrossRef]

7. Pournamdari, M.; Hashim, M.; Pour, A.B. Application of ASTER and Landsat TM data for geological mapping of Esfandagheh ophiolite complex, southern Iran. Resour. Geol. 2014, 64, 233-246. [CrossRef]

8. Masoumi, F.; Eslamkish, T.; Honarmand, M.; Abkar, A.A. A comparative study of Landsat-7 and Landsat-8 data using image processing methods for hydrothermal alteration mapping. Resour. Geol. 2017, 67, 72-88. [CrossRef]

9. Francis, P.; Rothery, D. Using the Landsat Thematic Mapper to detect and monitor active volcanoes: An example from lascar volcano, northern Chile. Geology 1987, 15, 614-617. [CrossRef]

10. Ranjbar, H.; Honarmand, M.; Moezifar, Z. Application of the Crosta technique for porphyry copper alteration mapping, using ETM+ data in the southern part of the Iranian volcanic sedimentary belt. J. Asian Earth Sci. 2004, 24, 237-243. [CrossRef]

11. Demirkesen, A.C. Quantifying geological structures of the Nigde province in central Anatolia, Turkey using SRTM DEM data. Environ. Geol. 2009, 56, 865-875. [CrossRef]

12. Crosta, A.; De Souza Filho, C.; Azevedo, F.; Brodie, C. Targeting key alteration minerals in epithermal deposits in Patagonia, Argentina, using ASTER imagery and principal component analysis. Int. J. Remote Sens. 2003, 24, 4233-4240. [CrossRef]

13. Rowan, L.C.; Mars, J.C.; Simpson, C.J. Lithologic mapping of the Mordor, NT, Australia ultramafic complex by using the Advanced Spaceborne Thermal Emission and Reflection Radiometer (ASTER). Remote Sens. Environ. 2005, 99, 105-126. [CrossRef]

14. Tangestani, M.H.; Jaffari, L.; Vincent, R.K.; Sridhar, B.M. Spectral characterization and ASTER-based lithological mapping of an ophiolite complex: A case study from Neyriz ophiolite, SW Iran. Remote Sens. Environ. 2011, 115, 2243-2254. [CrossRef]

15. Son, Y.S.; Kang, M.K.; Yoon, W.J. Lithological and mineralogical survey of the Oyu Tolgoi region, southeastern Gobi, Mongolia using ASTER reflectance and emissivity data. Int. J. Appl. Earth Obs. Geoinf. 2014, 26, 205-216. [CrossRef]

16. Ninomiya, Y.; Fu, B. Regional lithological mapping using ASTER-TIR data: Case study for the Tibetan Plateau and the surrounding area. Geosciences 2016, 6, 39. [CrossRef]

17. Pesaresi, M.; Corbane, C.; Julea, A.; Florczyk, A.J.; Syrris, V.; Soille, P. Assessment of the added-value of Sentinel-2 for detecting built-up areas. Remote Sens. 2016, 8, 299. [CrossRef]

18. Navarro, G.; Caballero, I.; Silva, G.; Parra, P.C.; Vázquez, Á.; Rui, C. Evaluation of forest fire on madeira island using Sentinel-2a MSI imagery. Int. J. Appl. Earth Obs. Geoinf. 2017, 58, 97-106. [CrossRef] 
19. Van der Meer, F.; van der Werff, H.; van Ruitenbeek, F. Potential of ESA's Sentinel-2 for geological applications. Remote Sens. Environ. 2014, 148, 124-133. [CrossRef]

20. Christian, M.; Kristine, B.N.; Christian, R.; Hermann, K.; Christoph, G.; Maarten, D.W. Spaceborne mine waste mineralogy monitoring in south Africa, applications for modern push-broom missions: Hyperion/OLI and EnMap/Sentinel-2. Remote Sens. 2014, 6, 6790-6816.

21. Van der Werff, H.; van der Meer, F. Sentinel-2 for mapping iron absorption feature parameters. Remote Sens. 2015, 7, 12635-12653. [CrossRef]

22. Yu, L.; Porwal, A.; Holden, E.J.; Dentith, M.C. Towards automatic lithological classification from remote sensing data using support vector machines. Comput. Geosci. 2012, 45, 229-239. [CrossRef]

23. Li, N.; Frei, M.; Altermann, W. Textural and knowledge-based lithological classification of remote sensing data in southwestern Prieska sub-basin, Transvaal supergroup, south Africa. J. Afr. Earth Sci. 2011, 60, 237-246. [CrossRef]

24. Metelka, V.; Baratoux, L.; Jessell, M.W.; Barth, A.; Jezek, J.; Naba, S. Automated regolith landform mapping using airborne geophysics and remote sensing data, Burkina Faso, west Africa. Remote Sens. Environ. 2018, 204, 964-978. [CrossRef]

25. De Boissieu, F.; Sevin, B.; Cudahy, T.; Mangeas, M.; Chevrel, S.; Ong, C.; Rodger, A.; Maurizot, P.; Laukamp, C.; Lau, I. Regolith-geology mapping with support vector machine: A case study over weathered Ni-bearing peridotites, New Caledonia. Int. J. Appl. Earth Obs. Geoinf. 2018, 64, 377-385. [CrossRef]

26. Windley, B.F.; Alexeiev, D.; Xiao, W.; Kröner, A.; Badarch, G. Tectonic models for accretion of the central Asian orogenic belt. J. Geol. Soc. 2007, 164, 31-47. [CrossRef]

27. Ao, S.; Xiao, W.; Han, C.; Li, X.; Qu, J.; Zhang, J.; Guo, Q.; Tian, Z. Cambrian to early Silurian ophiolite and accretionary processes in the Beishan collage, NW China: Implications for the architecture of the southern Altaids. Geol. Mag. 2012, 149, 606-625. [CrossRef]

28. Zheng, R.; Wu, T.; Zhang, W.; Xu, C.; Meng, Q. Late Paleozoic subduction system in the southern central Asian orogenic belt: Evidences from geochronology and geochemistry of the Xiaohuangshan ophiolite in the Beishan orogenic belt. J. Asian Earth Sci. 2013, 62, 463-475. [CrossRef]

29. Jolivet, M. Mesozoic tectonic and topographic evolution of central Asia and Tibet: A preliminary synthesis. Geol. Soc. Lond. Spec. Publ. 2017, 427, 19-55. [CrossRef]

30. Davis, G.A.; Marc, S. Paleozoic and Mesozoic Tectonic Evolution of Central and Eastern Asia; Geological Society of America: Boulder, CO, USA, 2001.

31. Xiao, W.; Windley, B.; Huang, B.; Han, C.; Yuan, C.; Chen, H.; Sun, M.; Sun, S.; Li, J. End-Permian to mid-Triassic termination of the accretionary processes of the southern Altaids: Implications for the geodynamic evolution, Phanerozoic continental growth, and metallogeny of central Asia. Int. J. Earth Sci. 2009, 98, 1189-1217. [CrossRef]

32. Xiao, W.; Han, C.; Liu, W.; Wan, B.; Zhang, J.e.; Ao, S.; Zhang, Z.; Song, D.; Tian, Z.; Luo, J. How many sutures in the southern central Asian orogenic belt: Insights from east Xinjiang-west Gansu (NW China)? Geosci. Front. 2014, 5, 525-536. [CrossRef]

33. Zuo, G.C.; Liu, Y.K.; Liu, C.Y. Framework and evolution of the tectonic structure in Beishan area across Gansu province, Xinjiang autonomous region and Inner Mongolia autonomous region. Acta Geol. Gansu 2003, 12, 1-15.

34. Drusch, M.; Del Bello, U.; Carlier, S.; Colin, O.; Fernandez, V.; Gascon, F.; Hoersch, B.; Isola, C.; Laberinti, P.; Martimort, P. Sentinel-2: ESA's optical high-resolution mission for GMES operational services. Remote Sens. Environ. 2012, 120, 25-36. [CrossRef]

35. Fujisada, H.; Iwasaki, A.; Hara, S. In ASTER stereo system performance. Proc. SPIE 2001, 4540, 39-49.

36. Barnett, P.J.; Singhroy, V.H.; Shirota, J.; Leney, S.J. Methods for remote engineering geology terrain analysis in boreal forest regions of Ontario, Canada. Environ. Eng. Geosci. 2004, 10, 229-241. [CrossRef]

37. Haykin, S.; Network, N. A comprehensive foundation. Neural Netw. 2004, 2, 41.

38. Hepner, G.; Logan, T.; Ritter, N.; Bryant, N. Artificial neural network classification using a minimal training set- comparison to conventional supervised classification. Photogramm. Eng. Remote Sens. 1990, 56, 469-473.

39. Thanh, P.N.; Kappas, M. Comparison of random forest, k-nearest neighbor, and support vector machine classifiers for land cover classification using Sentinel-2 imagery. Sensors 2017, 18, 18. [CrossRef] [PubMed]

40. Qian, Y.; Zhou, W.; Yan, J.; Li, W.; Han, L. Comparing machine learning classifiers for object-based land cover classification using very high resolution imagery. Remote Sens. 2014, 7, 153-168. [CrossRef] 
41. Wang, F.; Zhen, Z.; Wang, B.; Mi, Z. Comparative study on KNN and SVM based weather classification models for day ahead short term solar pv power forecasting. Appl. Sci. 2017, 8, 28. [CrossRef]

42. Chen, X.; Warner, T.A.; Campagna, D.J. Integrating visible, near-infrared and short-wave infrared hyperspectral and multispectral thermal imagery for geological mapping at Cuprite, Nevada. Remote Sens. Environ. 2007, 110, 344-356. [CrossRef]

43. Mondal, A.; Kundu, S.; Chandniha, S.K.; Shukla, R.; Mishra, P. Comparison of support vector machine and maximum likelihood classification technique using satellite imagery. Int. J. Remote Sens. GIS 2012, 1, 116-123.

44. Zhang, X.; Pazner, M.; Duke, N. Lithologic and mineral information extraction for gold exploration using ASTER data in the south chocolate mountains (California). ISPRS J. Photogramm. Remote Sens. 2007, 62, 271-282. [CrossRef]

45. Scott, A.J.; Symons, M.J. Clustering methods based on likelihood ratio criteria. Biometrics 1971, $387-397$. [CrossRef]

46. Ougiaroglou, S.; Diamantaras, K.I.; Evangelidis, G. Exploring the effect of data reduction on neural network and support vector machine classification. Neurocomputing 2018, 280, 101-110. [CrossRef]

47. Otukei, J.R.; Blaschke, T. Land cover change assessment using decision trees, support vector machines and maximum likelihood classification algorithms. Int. J. Appl. Earth Obs. Geoinf. 2010, 12, S27-S31. [CrossRef]

48. Cortes, C.; Vapnik, V. Support-vector networks. Mach. Learn. 1995, 20, 273-297. [CrossRef]

49. Ramirez-Lopez, L.; Behrens, T.; Schmidt, K.; Stevens, A.; Demattê, J.A.M.; Scholten, T. The spectrum-based learner: A new local approach for modeling soil VIS-NIR spectra of complex datasets. Geoderma 2013, 195, 268-279. [CrossRef]

50. Gholizadeh, A.; Boruvka, L.; Saberioon, M.; Vašát, R. A memory-based learning approach as compared to other data mining algorithms for the prediction of soil texture using diffuse reflectance spectra. Remote Sens. 2016, 8, 341. [CrossRef]

51. Othman, A.; Gloaguen, R. Improving lithological mapping by SVM classification of spectral and morphological features: The discovery of a new chromite body in the Mawat ophiolite complex (Kurdistan, NE Iraq). Remote Sens. 2014, 6, 6867-6896. [CrossRef]

52. Cutler, D.R.; Edwards, T.C.; Beard, K.H.; Cutler, A.; Hess, K.T.; Gibson, J.; Lawler, J.J. Random forests for classification in ecology. Ecology 2007, 88, 2783-2792. [CrossRef] [PubMed]

53. Oliveira, S.; Oehler, F.; San-Miguel-Ayanz, J.; Camia, A.; Pereira, J.M. Modeling spatial patterns of fire occurrence in mediterranean europe using multiple regression and random forest. Forest Ecol. Manag. 2012, 275, 117-129. [CrossRef]

54. Rodriguez-Galiano, V.F.; Ghimire, B.; Rogan, J.; Chica-Olmo, M.; Rigol-Sanchez, J.P. An assessment of the effectiveness of a random forest classifier for land-cover classification. ISPRS J. Photogramm. Remote Sens. 2012, 67, 93-104. [CrossRef]

55. Breiman, L. Random forests. Mach. Learn. 2001, 45, 5-32. [CrossRef]

56. Heil, J.; Michaelis, X.; Marschner, B.; Stumpe, B. The power of random forest for the identification and quantification of technogenic substrates in urban soils on the basis of drift spectra. Environ. Pollut. 2017, 230, 574-583. [CrossRef] [PubMed]

57. Cohen, J. A coefficient of agreement for nominal scales. Educ. Psychol. Meas. 1960, 20, 37-46. [CrossRef]

58. Tang, Y.; Jing, L.; Li, H.; Liu, Q.; Yan, Q.; Li, X. Bamboo classification using Worldview-2 imagery of giant panda habitat in a large shaded area in Wolong, Sichuan province, China. Sensors 2016, 16, 1957. [CrossRef] [PubMed]

59. Sun, X.; Yang, Z. Generalized mcnemar's test for homogeneity of the marginal distributions. In Proceedings of the SAS Global Forum, San Antonio, TX, USA, 16-19 March 2008; pp. 1-10.

60. Foody, G.M. Thematic map comparison. Photogramm. Eng. Remote Sens. 2004, 70, 627-633. [CrossRef]

61. Abrams, M.J.; Rothery, D.A.; Pontual, A. Mapping in the Oman ophiolite using Enhanced Landsat Thematic Mapper images. Tectonophysics 1988, 151, 387-401. [CrossRef]

62. Rowan, L.C.; Mars, J.C. Lithologic mapping in the mountain pass, California area using Advanced Spaceborne Thermal Emission and Reflection Radiometer (ASTER) data. Remote Sens. Environ. 2003, 84, 350-366. [CrossRef]

63. Di Tommaso, I.; Rubinstein, N. Hydrothermal alteration mapping using ASTER data in the Infiernillo porphyry deposit, Argentina. Ore Geol. Rev. 2007, 32, 275-290. [CrossRef] 
64. Mars, J.C.; Rowan, L.C. Spectral assessment of new ASTER SWIR surface reflectance data products for spectroscopic mapping of rocks and minerals. Remote Sens. Environ. 2010, 114, 2011-2025. [CrossRef]

65. Ayoobi, I.; Tangestani, M.H. The effect of minimum noise fraction data input on success of artificial neural network in lithological mapping of a magmatic terrain with ASTER data; a case study from SE Iran. Remote Sens. Appl. Soc. Environ. 2017, 7, 21-26. [CrossRef]

66. Leverington, D.W.; Moon, W.M. Landsat-TM-based discrimination of lithological units associated with the Purtuniq ophiolite, Quebec, Canada. Remote Sens. 2012, 4, 1208-1231. [CrossRef]

67. Grebby, S.; Field, E.; Tansey, K. Evaluating the use of an object-based approach to lithological mapping in vegetated terrain. Remote Sens. 2016, 8, 843. [CrossRef]

68. Wei, J.; Liu, X.; Liu, J. Integrating textural and spectral features to classify silicate-bearing rocks using Landsat 8 data. Appl. Sci. 2016, 6, 283. [CrossRef]

69. Iqbal, A.; Ullah, S.; Khalid, N.; Ahmad, W.; Ahmad, I.; Shafique, M.; Hulley, G.C.; Roberts, D.A.; Skidmore, A.K. Selection of HyspIRI optimal band positions for the earth compositional mapping using HyTes data. Remote Sens. Environ. 2018, 206, 350-362. [CrossRef]

(C) 2018 by the authors. Licensee MDPI, Basel, Switzerland. This article is an open access article distributed under the terms and conditions of the Creative Commons Attribution (CC BY) license (http://creativecommons.org/licenses/by/4.0/). 